\title{
Evaluation of Shear Dilation Capability/Potential and Permeability Changes in Karamay Oil Sands under Water Injection
}

\author{
Yanfang Gao, ${ }^{1,2}$ Huiwen Pang, ${ }^{1,2}$ Yan Jin $\mathbb{D D}^{1,2}$ and Mian Chen ${ }^{1,2}$ \\ ${ }^{1}$ State Key Laboratory of Petroleum Resources and Prospecting, Beijing 102249, China \\ ${ }^{2}$ College of Petroleum Engineering, China University of Petroleum, Beijing 102249, China
}

Correspondence should be addressed to Yan Jin; jiny902@126.com

Received 24 January 2019; Revised 13 May 2019; Accepted 16 July 2019; Published 25 November 2019

Academic Editor: Ricardo L. Silva

Copyright ( 2019 Yanfang Gao et al. This is an open access article distributed under the Creative Commons Attribution License, which permits unrestricted use, distribution, and reproduction in any medium, provided the original work is properly cited.

\begin{abstract}
Water injection can effectively improve the reservoir porosity and permeability by shear dilation in the vicinity of wellbores. In this paper, shear dilation and permeability improvement capability/potential are proposed to describe the evolutions of porosity and permeability under water injection-induced shear. The mathematical models based on Karamay oil sand microstructures derived from ESEM (environmental scanning electron microscope) are established to predict the shear dilation effects based on the particle packing theory. Triaxial compression and permeability experiments are conducted to validate the theoretical models, and the experimental data is consistent with model results. Also, the study compares shear dilation capabilities evaluated from three scales: ESEM $(\mu \mathrm{m})$, laboratory triaxial compression tests $(\mathrm{cm})$, and field injection tests $(\mathrm{m})$. Major conclusions through an application on the wellpair A-2 in area A of the Karamay oil field showed that the oil sands have an excellent shear dilation potential. The larger arrangement angle results in stronger shear dilation and permeability, which means a lower arrangement angle provides a higher potential for improvement. The shear dilation capabilities predicted by ESEM, triaxial compression experiments, and field injection data descend in turn, which indicates that the actual shear dilation capability is difficult to be utilized by present field operations.
\end{abstract}

\section{Introduction}

Oil sands have been defined as a kind of porous media that contain an extremely viscous hydrocarbon which is not recoverable in its natural state by conventional EOR (enhanced oil recovery) methods [1]. They are highly dilatant materials which possess common characteristics of very dense sands. Most of the oil sands in the world, mainly located in Alberta (Canada), Venezuela, and Xinjiang (China), are all bituminous unconsolidated sandstones. They are regarded as unique engineering materials based on two reasons: firstly, bitumen is essentially the original solid, and secondly, the sands are not loosely unconsolidated beach sands $[2,3]$. The virginal marine Alberta oil sands are characterized by a microstructure of the tangent-to-tangent grain interaction and possess a special glacier action-induced interlocked structure just like overconsolidated soil $[4,5]$. How- ever, oil sands in Karamay, Xinjiang, have a terrestrial unconsolidated and interlocked structure like but not as dense as Alberta oil sands [6], which are formed in deep burial depth and elevated temperature over geological time [2]. These special structures make it possible for oil sands to expand in volume by shear dilation and tensile parting dilation during thermal stimulations [7]. To date, the use of geomechanics in enhancing the SAGD (steam-assisted gravity drainage) process, especially for the startup phase (i.e., water injection and steam circulation prior to the oil production phase), has drawn widespread attention and resulted in extensive research, technical discussions, and field applications, mostly focusing on the oil sands in Alberta, Canada [8].

When water is injected into the domain between dual wells, the geomechanical behavior of the geomaterial under artificial operations is the key element governing the injectivity of fluid and consequently the propagation of fractures [9]. 
The important features are the dilatant behavior of oil sands associated with volumetric strain and the change of fluid transport properties (e.g., the porosity and permeability as a function of effective stress and sand failure) [9]. The porosity and permeability increase due to dilation is the primary mechanism for fluid injectivity [9-11]. The fact that dilatant behavior is observed even at $8 \mathrm{MPa}$ effective confining stress is indicative of the influence of the locked sand grain structure [12]. The material property which greatly influences the process of SAGD is a dense sand propensity for dilation under the application of shear stress. Dilation refers to the process of pore volume expansion as neighboring sand grains attempt to move past each other under the action of shear stresses within the formation. The nearly pure quartzitic nature of the sand grains ensures that no grain crushing occurs during shear [13]. Pore pressure increases during water or steam injection, decreases the effective confining stress, and results in an unloading of the reservoir matrix. For an anisotropic in situ stress state, pore pressure injection will potentially generate shear strains in the reservoir. These processes can combine to result in a net change in the reservoir pore volume and permeability [14].

There are two widely used approaches for studying the relation of oil sand microstructures (e.g., pore structures and oil sand grain arrangements) and fluid transport properties (e.g., porosity and permeability). Firstly, experimental investigations involving microstructure researches and triaxial compression tests were widely employed. Leung et al. [15] exhibited an innovative method which can visualize and calculate the porosity distribution in a sheared sample. Wong et al. [16] demonstrated that the mode of shear dilationinduced deformation corresponds to the relative motion between groups of particles facilitated by the sliding mechanism, and a significant amount of energy is used to overcome the frictional forces between contacts in the sliding-dilation orientation and to expand the pore volume against the confining stress. Scott et al. [17] discovered that the volume and permeability changes are the results of three effects: a change in the mean principal effective stress, a change in the shear stress, and a change in temperature. Wong [18] visualized the internal microscopic deformations such as an interlocked structure, shear banding, grain arrangement, and porosity spatial distribution, to explain and quantify how the global average deformation behavior of Athabasca oil sands observed in triaxial compression is affected by the local microstructural deformation. Yuan et al. [7] concluded that the dilated zone is created by shear dilation (rolling of sand grains over each other when sheared) and tensile parting (when the increased injection pressure reduces the effective stresses at the locations close to the wellbore and creates tensile microcracks). Doan et al. [19] studied the microstructural characterization of a Canadian oil sand, and evidence of some dense areas composed of highly angular grains surrounded by fluids and (frozen) bitumen clearly appear between sand grains.

Touhidi-Baghini [20] and Touhidi-Baghini and Scott [21] used specimens cored vertically and horizontally from a block sample of oil sands from the McMurray formation and used the constant flow rate method to quantify the change in absolute permeability of these locked sand specimens due to triaxial compression tests at low confining stresses. Volumetric strain and permeability were measured during these tests, and 2 to 8 fold increases in permeability were found for 2 to 8 percent volumetric dilation. Oldakowski [22] studied the stress-induced permeability changes of cold, bitumen-rich Athabasca oil sands, and the relation between water saturation and the effective permeability to water was investigated. Yale et al. [23] conducted many triaxial compression tests and proposed theoretical models to analyze the permeability increase due to dilation. Xu [24] found that the Karamay oil sands deform more like normally consolidated sands: there were no obvious shear fractures after the triaxial tests and there was very small or no volumetric dilation measured during the triaxial tests. Lin et al. [8] showed that the considerably less consolidated Karamay oil sands have a loosely packed structure with sand grains isolated by bitumen and clay, which distinguishes them from the interlocked grain structure of the Alberta oil sands. The dilation mechanisms of terrestrial Karamay oil sands under water injection were studied by experimental investigations. These experiments studied the volumetric dilation behaviors of oil sands under different test conditions and were designed to find a qualitative relation between the global average deformation behavior involving the changes in porosity and permeability and the microstructures derived from the physical microscopic electronic images.

The theoretical models, mainly based on the particle packing approaches, were used to quantitatively establish a direct relation between microstructures and global porosity as well as permeability. At first, many researchers discussed the systematic packing of spheres with a particular relation between porosity and permeability $[25,26]$. Then, Wong and $\mathrm{Li}$ [27] presented an analytical relationship between permeability and stress/strain under elastic contact deformation and shear dilation by a granular assembly with regular rhombic packing. Wong [28] further developed an approach that allows one to formulate the evolution of changes in permeability in three directions under continuous shearing. The model explicitly stated that the permeability changes are anisotropic and dependent on the induced strains. Although these theoretical models are very useful and simple for engineers to evaluate the deformation induced by shear dilation, there are still more shortcomings for the theoretical models (based on plenty of scientific assumptions) than the experimental studies (based on actual microstructure images and global deformation of test samples).

The preliminary evaluation methods concerning shear dilation and permeability changes under water injection were individually discussed in terms of oil sand microstructures, macroscopic deformations of cores (through a triaxial compression test), and the applications in field practices. For getting a more reasonable and practicable evaluation model that can not only embody the physical microstructures instead of pure ideal assumptions but also establish a direct mathematical relation between global flow properties and essential microstructures (e.g., sand grain arrangements), this article proposed both two- and three-dimensional evaluation models to obtain two useful defined parameters (i.e., shear 
dilation and permeability improvement capability/potential), based on adequate previous background studies on the petrophysical properties of Karamay oil sands. The evaluation methods in this study can not only predict the maximum shear dilation capability (potential) and permeability evolutions according to the microscopic electronic images even prior to artificial operations but also analyze the shear dilation and permeability improvement effects under water injection by constantly detecting the wellhead flow rate.

\section{Material}

Oil sands are composed of mineral solids, water, bitumen, and gases [29]. The oil sands in Karamay are filled with rich viscous bitumen, which keeps a solid state in initial reservoir conditions. The bitumen that fills in the pores is usually regarded as a part of a skeleton. At a reservoir temperature of $18.5^{\circ} \mathrm{C}$, the skeleton of oil sand can be viewed as a granular assembly with the cement composed of clay and bitumen [3, $24,30]$, and the pore fluids that can change the pore pressures only include water and gases. The mechanical behaviors of oil sands are very dependent on their compositions, microstructures, and petrophysical properties. In this study, the composition, porosity, permeability, and bitumen characteristics of Karamay oil sands were investigated. All the experiments were conducted in the State Key Laboratory of Petroleum Resources and Prospecting, Beijing, China. All the used samples were collected at a depth of 303 304 m in the Qigu formation of the Fengcheng oilfield, Karamay, Xinjiang, China.

\subsection{Mineral Compositions. An X-ray spectrometer (Oxford} Link ISIS 300) was used to analyze the mineral compositions of Karamay oil sands. The bitumen in the oil sand samples (with $6.6 \%$ bitumen) was first washed, and the pure inorganic mineral substances were used for further analyses. The results are shown in Figure 1.

As shown in Figure 1, the Karamay oil sand consists of twelve minerals (represented by the numbers from 1 to 12 , respectively). The main minerals of the Karamay oil sands are quartz, feldspar, dolomite, illite, kaolinite, and chlorite. Quartz and feldspar are the two main compositions, accounting for $35 \%$ and $20 \%$, respectively. The highcontent quartz means that the Karamay oil sands are a highly hydrophilic instead of an oleophilic geomaterial. The low-content smectite and illite-smectite mixed layer makes the Karamay oil sands possess a weak water sensitivity. The clay mineral accounts for $30.7 \%$, which means a possibly low permeability.

According to Figure 1, the oil sands are not dominantly quartzic. However, the grain-crushing deformation only occurs at such a high stress that the contact forces can cause the breakage of individual grains. The triaxial compression tests and the ESEM images after shear at the reservoir stress conditions demonstrated a slight possibility of grain crushing. In this regard, the high-content quartzitic nature sand grains ensure that little grain crushing occurs. Therefore, the volumetric dilation mechanism is dominated by slidinginduced shear dilation.

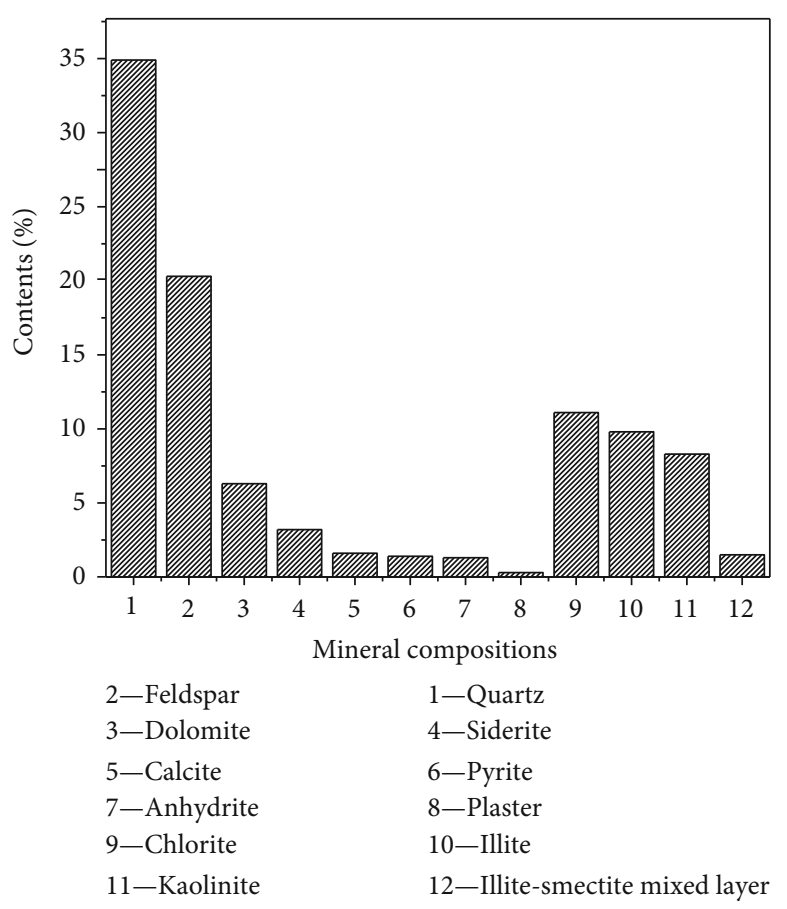

Figure 1: Mineral compositions of Karamay oil sands.

2.2. Porosity and Permeability. The particle size and porosity properties were investigated. The laser nanoparticle size analyzer (Zetasizer Nano ZS) was used for determining the PSD (particle size distributions) of Karamay oil sands after the bitumen in pores was washed. Both the wet method and dry method, dispersing pulverous oil sand samples in liquid and gas, respectively, were adopted. The particle size distributions are shown in Figure 2. The porosity of Karamay oil sands with bitumen was tested by the automatic ratio surface and aperture analyzer (ASAP2020M). It is worth noting that the porosity of Karamay oil sands under water injection is much lower than that under oil production, because the solid bitumen plays a role of a skeleton instead of a pore fluid. The porosity test results of the three samples are shown in Table 1. Permeability tests were conducted using the instantaneous pressure pulse permeability measuring instrument attached to the Geotechnical Consulting and Testing Systems (GCTS RTR-1500). The permeability test results are shown in Figure 3.

There may be some uncertainty associated with the methods used for the calculation of the PSD parameters. For example, the methods of sieving or DIA (digital image analysis) can also be used for the PSD analyses. Lin et al. [8] used the sieving method for the PSD analysis of Karamay oil sands and exhibited many ESEM images, which can be employed for counting the numbers of particles in different sizes. From Figure 2, another studied oil sand sample (without bitumen) has about $20 \%$ clay, $60 \%$ silt, and $20 \%$ sand. The mass of oil sand grains that have possible potentials to be dilated under shear (particle size $\geq 10 \mu \mathrm{m}$ ) is more than $80 \%$, which means that the Karamay oil sands have an excellent dilation potential if some adequate measures can be taken for a reservoir stimulated by artificial operations. It is 


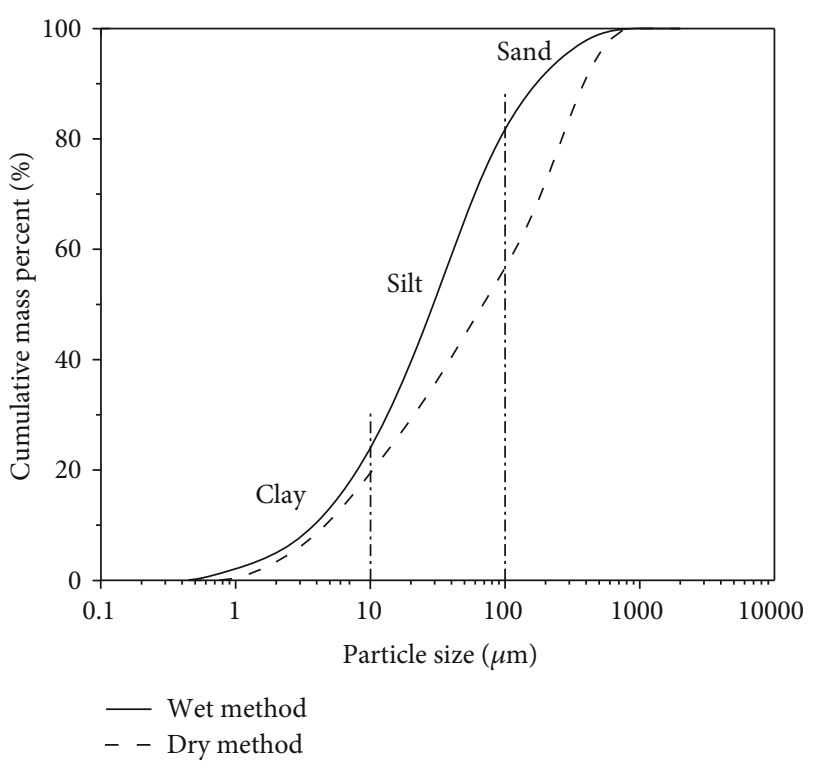

FIgure 2: Particle size distributions of Karamay oil sands.

worth noting that the cumulative mass percent tested by the wet method is a little higher than that tested by the dry method. The possible reason is that the studied oil sand possesses many mineral compositions that can react or deform easily with water or other liquids.

In this table, the average porosity with bitumen considered as part of the pore space or with bitumen excluded was measured by a number of oil sand specimens, while the porosity values (excluding bitumen) in the last two columns were measured by only one typical oil sand specimen, which was used to conduct the triaxial compression tests to obtain the porosity after shear.

The high-content oil sand grains give the Karamay oil sands a high porosity. The average porosity with the bitumen being considered as part of the pore space is from 0.33 to 0.37 , and the bitumen-rich oil sands seem to exhibit a higher value than regular and mud-rich oil sands. However, the bitumen under reservoir condition and even under water injection (normally from 20 to $80^{\circ} \mathrm{C}$ ) is too viscous to flow, so another porosity named the porosity excluding bitumen is always used for reservoir geomechanical analyses $[3,8$, 30]. The average porosity excluding bitumen ranges from 0.13 to 0.17 , and the bitumen-rich oil sand shows a lower value than others.

Some experiments were conducted to find evidence that the porosity (excluding bitumen) increase exists under water injection. The expansion mechanisms in this process are proven to be shear dilation and tensile parting expansion $[7,8]$. The dilation is mainly caused by shear yielding. In this paper, only shear dilation was focused on. From the test results, the regular and bitumen-rich oil sands both show very significant dilation capabilities under shear. In particular, the shear dilation-induced porosity increases by 0.05 for the regular oil sand. The mud-rich oil sand shows a lower shear dilation capability. The discussions above show enough evidence of considerable shear dilation capability or potential for Karamay oil sands.
Permeability is a direct parameter for the evaluation of the flow capabilities in SAGD phases. The effective permeability to water is usually used in the process of water injection, because the bitumen in this process can hardly flow. The permeability improvements before and after shear are exhibited in Figure 3. Types 1, 2, and 3 represent the regular, mud-rich, and bitumen-rich oil sands, respectively. $V$ and $H$ denote the vertical and horizontal cored specimens, respectively. The method of liquid nitrogen coring was adopted to obtain $25 \mathrm{~mm}$ (diameter) $\times 50 \mathrm{~mm}$ (length) cylinders along and perpendicular to the axis of the field-collected cores sampled from vertical wells. The detailed coring process was described in Lin et al. [8]. The fast pulse-decay apparatus was used to measure the permeability of oil sand samples under shear. The calculation equation is $k=(\mu \beta V L / 2 A)$ $\left(\lg \left(\Delta p_{\mathrm{i}}-\Delta p_{\mathrm{f}}\right) / t_{\mathrm{f}}-t_{\mathrm{i}}\right)$. Here, $\mu$ is the dynamic viscosity of a liquid; $\beta$ is the volume compression coefficient; $V$ is the liquid volume; $A$ and $L$ are the cross-sectional area and length, respectively; $\Delta p_{i}$ and $\Delta p_{f}$ are the initial and ultimate differential pressures of a pore fluid between two ends, respectively; and $t_{i}$ and $t_{f}$ are the starting time and ending time of the test, respectively.

Figure 3 shows the permeability magnitudes before and after these triaxial compression tests at several typical effective confining stresses $(0.5,1,2$, and $5 \mathrm{MPa}$, as the horizontal axis shows). The permeabilities were firstly measured before these tests (when the effective confining pressure $=0 \mathrm{MPa}$ ). Then, the oil sand specimens were used for the triaxial compression tests under different effective confining pressures. At the end of these experiments (the experiments were stopped when the axial strain was 9\%), the ultimate permeability was tested.

Many people considered that the permeability of oil sand is relatively high, and the propagation of pore pressure makes it easy for shear dilation to occur. In reality, the initial reservoir effective permeability to water is relatively low because of the presence of solid bitumen. The regular oil sand has a relatively higher permeability (about $2886 \mu \mathrm{D}$ ) than mud- and bitumen-rich oil sands (several hundred $\mu \mathrm{D}$ ). The horizontal permeability is lower than the vertical one. For example, the vertical permeability of the Karamay regular oil sands is $2886 \mu \mathrm{D}$, while the horizontal is only $444 \mu \mathrm{D}$; the vertical permeability of the Karamay bitumen-rich oil sands is $180 \mu \mathrm{D}$, while the horizontal is only $121 \mu \mathrm{D}[8,32]$. After shear dilation under a relatively lower effective confining stress $(0.5$, 1 and $2 \mathrm{MPa}$ ), the permeability is improved to some degree. The vertical permeability of the regular oil sands nearly doubles. However, the permeability under an effective confining stress of $5 \mathrm{MPa}$ decreases because of shear compaction effects. The results tell us that the shear dilation capability under a relatively lower effective confining stress is better.

2.3. Microstructure Characteristics. For interpreting the shear dilation mechanisms of Karamay oil sands, the microstructures before and after shear were investigated by the ESEM (FEI Quanta 200F). The ESEM experiments can obtain the original Karamay oil sands with water and bitumen, so it can embody the real microstructures of oil sands under water 
TABle 1: Porosity experiments of Karamay oil sands [31].

\begin{tabular}{|c|c|c|c|c|}
\hline \multirow{2}{*}{ Sample } & \multirow{2}{*}{ Average porosity* } & \multirow{2}{*}{$\begin{array}{l}\text { Average porosity } \\
\text { excluding bitumen }\end{array}$} & \multicolumn{2}{|c|}{ Dilation-induced porosity by experiments } \\
\hline & & & Shear & Tensile parting \\
\hline Regular oil sand & 0.33 & 0.17 & $0.23 \rightarrow 0.28$ & $0.22 \rightarrow 0.24$ \\
\hline Mud-rich oil sand & 0.33 & 0.16 & $0.22 \rightarrow 0.23$ & $0.21 \rightarrow 0.21$ \\
\hline Bitumen-rich oil sand & 0.37 & 0.13 & $0.18 \rightarrow 0.20$ & $0.11 \rightarrow 0.19$ \\
\hline
\end{tabular}

* Porosity with the bitumen being considered as part of the pore space.

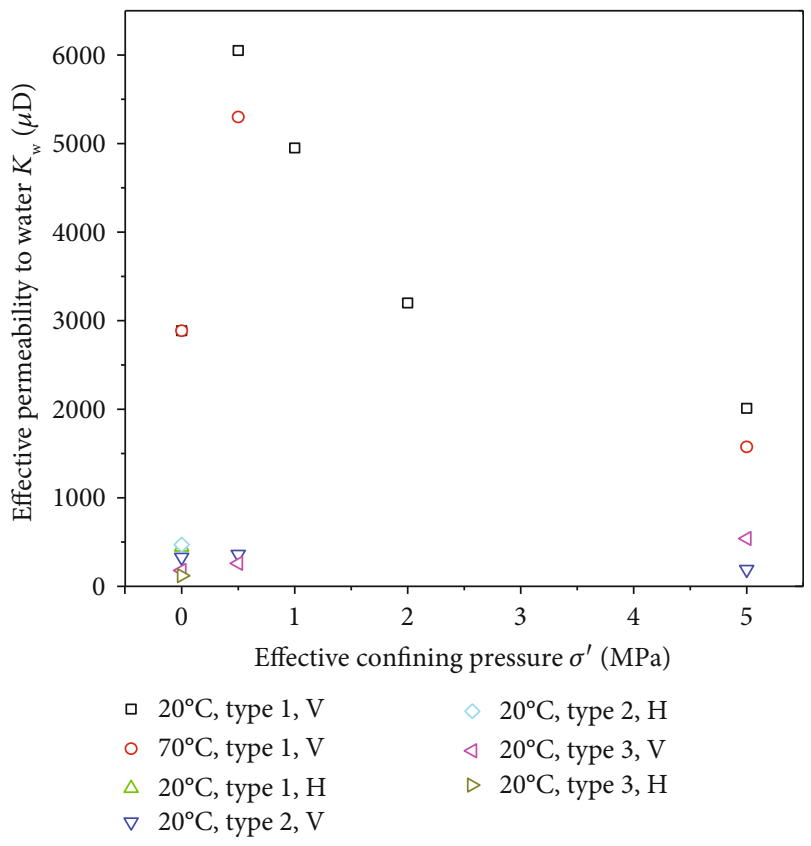

Figure 3: Permeability of Karamay oil sands before $\left(\sigma^{\prime}=0\right)$ and after $\left(\sigma^{\prime}>0\right)$ triaxial compression tests under varying confining pressures.

injection. Figure 4 shows the comparisons of the microstructures of Karamay oil sands before and after shear. Figures 4(a) and 4(b) exhibit the initial oil sand structures before shear, and their magnifications are 100 and 320 times, respectively. Figures $4(\mathrm{c})$ and $4(\mathrm{~d})$ display the disturbed oil sand structures after shear at an effective confining stress of $0.5 \mathrm{MPa}$, and their magnifications are 100 and 320 times, respectively.

The microstructures of the initial oil sands (Figures 4(a) and 4(b)) show that the solid grains with a large particle size are surrounded by the mixtures of bitumen and clay. The original structures are loosely packed, and the intergranular contact points and interfaces seem very few, which means that the shear dilation capability is not very apparent at first until these grains sufficiently contact with each other under adequate operations by water injection. The breccia-shaped oil sand grains have sharp edges and form an interlocked structure, which indicate a high shear dilation potential. After shear dilation under a low effective confining stress of $0.5 \mathrm{MPa}$, the shear band occurs apparently (Figures 4(c) and $4(\mathrm{~d}))$. The oil sand grains slide under shear stress and generate some large intergranular pores, leading to a high porosity and permeability.

2.4. Bitumen Characteristics. The bitumen in the Karamay oil sands are in a semisolid or solid state in the process of water injection, so it cannot flow at all before steam injection. The bitumen in Karamay oil sand has possible roles as a pore fluid, skeleton, or cement, depending on the reservoir environments in different SAGD phases. The role of the pore fluid can be easily understood (when bitumen can flow). The initial viscosity of Karamay bitumen ranges from $10^{5}$ to $10^{6} \mathrm{mPa} \cdot \mathrm{s}$. The temperature increase induced by steam injection can effectively decrease the viscosity of bitumen. Relations between temperature and the viscosity of the bitumen collected from several typical SAGD wells are shown in Figure 5. In general, the bitumen viscosity at a certain temperature is determined by its components. The more macromolecules (asphaltenes and resins) there are, the more viscous the bitumen is. To know the components of the bitumen abstracted from the Karamay oil sands, the mass contents of asphaltenes, resins, aromatics, and saturates were tested according to ASTM (American Society for Testing Materials) [33]. The test results are shown in Figure 6.

As shown in Figure 5, the viscosity of Karamay bitumen drops sharply with an increase in temperature. In the reservoir condition, the viscosity of bitumen in Well \#6 reaches as high as $6 \times 10^{4} \mathrm{mPa} \cdot \mathrm{s}$ and the viscosity in Well \#2 dramatically reaches as high as $2 \times 10^{6} \mathrm{mPa} \cdot \mathrm{s}$. This means that the Karamay bitumen cannot flow at all and always stays in its initial position under a water injection temperature of 20 $80^{\circ} \mathrm{C}$. In the SAGD process, when the viscosity of crude oil drops to a critical value of $1000 \mathrm{mPa} \cdot \mathrm{s}$, the drained zone forms and it is not very difficult for the pore fluids to flow under some driving forces [34]. In order to achieve this, the reservoir should be heated to at least $75 \sim 140^{\circ} \mathrm{C}$ for different wells. The viscosity of Karamay heavy oil ultimately drops to a value of less than $10 \mathrm{mPa} \cdot \mathrm{s}$, which is absolutely favorable for oil production. The bitumen in the process of water injection plays a role as a skeleton and cement, and it can affect the shear dilation capability to some degree. As shown in Figure 4(d), the sliding of oil sand grains forces the intergranular mixtures of clay and bitumen to be dislocated, leading to the collapse or expansion of the primary pores. The degree of this behavior shown in Figure 4(d) is dependent upon the intergranular cementing strength, which is related to the content of asphaltenes and resins. Figure 6 shows the separation of Karamay bitumen into four fractions. As shown in Figure 6, the asphaltenes and resins of Karamay bitumen 


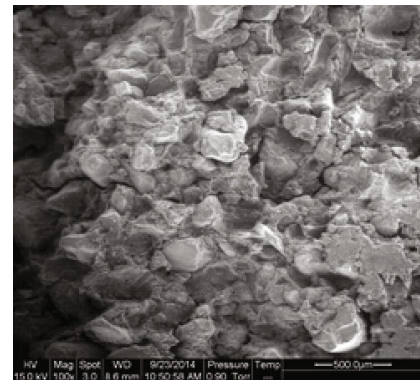

(a)

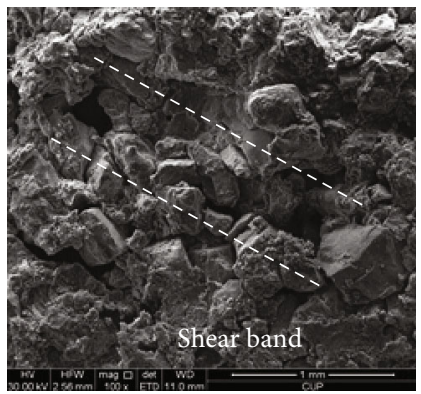

(c)

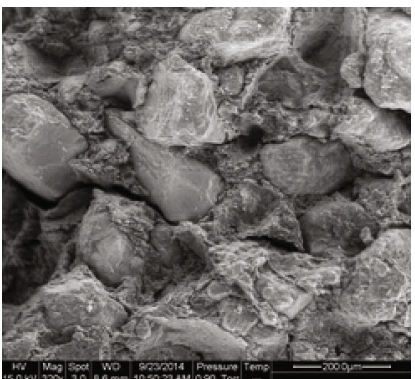

(b)

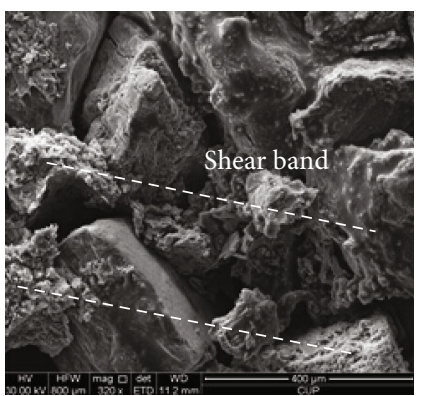

(d)

FIGURE 4: Microstructures of Karamay oil sands before and after shear dilation.

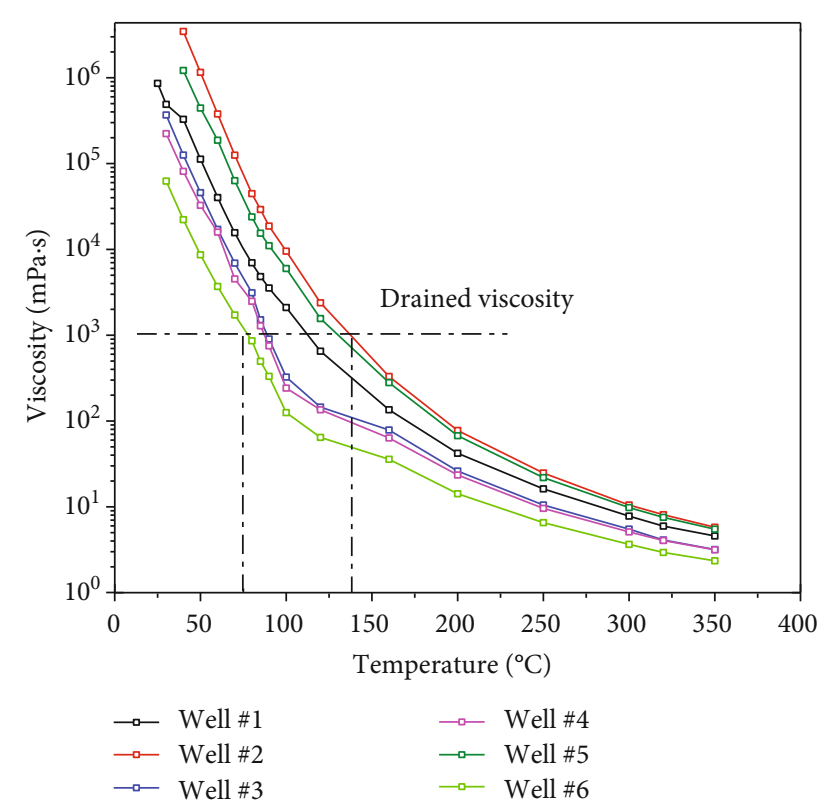

Figure 5: Relations of viscosity and temperature of Karamay bitumen.

account for $20.87 \%$ and $27.42 \%$, respectively. It means that the cementing strength caused by viscous bitumen is very high.

\section{Method}

The oil sands, one kind of unconsolidated sandstones, are comprised of solid grains, cements, and pore fluids. The dilation occurs by the sliding of solid grains with similar diameters. For quantitatively simulating the shear dilation behaviors during the SAGD process, the oil sands are always simplified into a problem of an accumulating body consisting of some spheroids with equal diameters [7, 16, 27, 28]. In this paper, this approach was also adopted. Some assumptions given for the model simplicity are as follows: the solid grains are isodiametric; the contact type between particles is point to point; the solid grains are incompressible; the pore fluids (bitumen, water, and gas) and clay are full of the intergranular pore spaces; and the particle packing state in any reservoir positions is the same.

Two parameters were defined for evaluating the shear dilation behavior, i.e., shear dilation and permeability improvement capability/potential. The term of capability is used for evaluating a given oil sand reservoir, in which the distribution of solid grains is already known. It means that the shear dilation and permeability improvement of given oil sand reservoirs from the initial state to the current disturbed state are caused by water injection. In other words, the capability is dependent upon the artificial operations. The term of potential is used for evaluating different oil sand reservoirs, in which the distribution of solid grains is different. It means the shear dilation and permeability improvement of different oil sand reservoirs from the initial state to the perfect disturbed state (the maximum shear dilation capability). The potential is only determined by the initial oil sand grain distributions and has nothing to do with the operations.

For a given reservoir and particle distribution, the current shear dilation capability (SDC) under different operations is defined as

$$
\mathrm{SDC}=\frac{V-V_{0}}{V_{0}},
$$




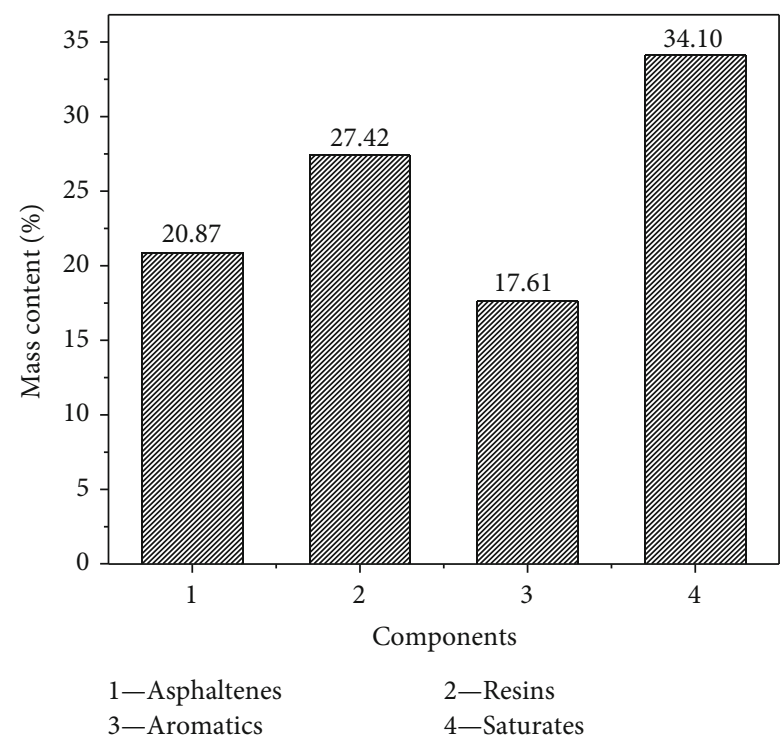

Figure 6: Separation of Karamay bitumen into four fractions.

where $V$ and $V_{0}$ are the current and initial total volumes, respectively. $V$ is a function of water injection-induced shear dilation, and $V_{0}$ is a constant. According to equation (1), a positive SDC means shear dilation, while a negative value means shear contraction.

For a given reservoir and particle distribution, the current permeability improvement capability (PIC) under different operations is defined as

$$
\mathrm{PIC}=\frac{k}{k_{0}}
$$

where $k$ and $k_{0}$ are the current and initial absolute permeabilities, respectively. $k$ is a function of shear under water injection, and $k_{0}$ is a constant. According to equation (2), a value $>1$ means permeability improvement, while a value $<1$ means permeability damage.

For different oil sand reservoirs, their particle distributions are different, and their shear dilation potentials (SDP) can be expressed as

$$
\mathrm{SDP}=\frac{V_{\max }-V_{\mathrm{i}}}{V_{\mathrm{i}}},
$$

where $V_{\max }$ and $V_{\mathrm{i}}$ are the perfect (maximum) and initial total volumes, respectively. $V_{\mathrm{i}}$ is a function of oil sand properties (i.e., the grain distribution), and $V_{\max }$ is a constant. SDP is always a positive value. If $\mathrm{SDP}=0$, it means no shear dilation potential; a greater SDP results in a higher shear dilation potential.

For different oil sand reservoirs, the permeability improvement potential (PIP) is defined as

$$
\mathrm{PIP}=\frac{k_{\max }}{k_{\mathrm{i}}}
$$

where $k_{\max }$ and $k_{\mathrm{i}}$ are the perfect (maximum) and initial absolute permeabilities, respectively. $k_{\mathrm{i}}$ is a function of oil sand grain distributions, and $k_{\max }$ is a constant. PIP is always greater than 1 . A value equal to 1 means no permeability potential; a greater PIP provides a higher permeability improvement potential.

In the next part, the evolutions of shear dilation and permeability improvement capability/potential will be employed to evaluate the effect of water injection by two-dimensional (2D) and three-dimensional (3D) models, respectively. The particle packing theory was used for these derivations from the microcosmic aspect.

3.1. Two-Dimensional Model. SAGD wells can be viewed as long cylinders in the oil sand reservoir, and the ratio of diameter to length is close to 0 . In this regard, the dilation behavior can be reduced as a plane strain problem. The pore pressures near SAGD wells are very high, while the pore pressures in far reservoir areas are close to the initial reservoir pressures, so the effective stresses (equal to total stresses subtracting pore pressures for oil sand reservoirs) are different in different zones. The shear stress occurs because of the difference of the effective stresses. The shear stresses exist in any of the planes perpendicular to the borehole axis, so the shear dilation occurs in a plane if the thickness of reservoir is 1 .

The average method was used to eliminate the differences of the solid grain diameter and irregularity. Based on the studies in Section 2 and previous studies on oil sands $[27,28]$, this study used the equal-diameter and periodically arranged particles to relatively accurately model the actual solid grains in oil sand reservoirs. In fact, the density function of probability can be used to see the probability of the occurrence of particles with a diameter of $d$. In Section 2.2, Figure 2 can be also plotted into a log-normal distribution curve, and this can be used to embody the difference of the solid grain diameter.

In this model, nine oil sand grains were used to form the representative area element (RAE). The area of the RAE was defined as the area of a closed parallelogram, whose four sides are right tangent to the edges of solid grains. On the top surface, the grains are sheared to the right; and on the bottom, they are sheared to the left. The lower right angle of these diamonds was defined as the arrangement angle $\alpha$ to describe the evolutions of the apparent area, density, or porosity of these RAEs. The three RAEs below can represent any particle packing states in the reservoir. The alpha is limited to more than 60 degrees.

According to the principle of minimum potential energy, the solid grains tend to have a more stable state in a weak cementing environment in the deposition process, so the most possible type of oil sand grain distributions in the process of granular deposition as well as hydrocarbon generation is exhibited in Figure 7(a). It is also very possible that the state shown in Figure 7(b) is the initial state if the sphericity and roughness of oil sand grains are high. When the geostresses change, the virgin particle packing body will be disturbed. If the shear stresses are forced on the RAE, the particle packing state will change to Figure $7(\mathrm{~b})$, until a 


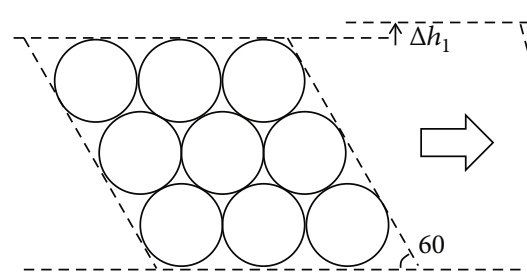

(a)

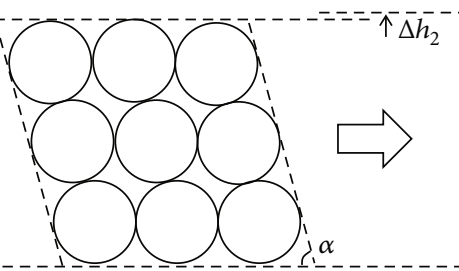

(b)

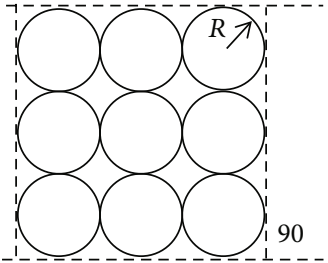

(c)

Figure 7: Two-dimensional evolutions of particle packing in the RAE.

perfect packing state is attained just like in Figure $7(\mathrm{c})$. In this paper, for evaluating the particle packing state, angle $\alpha$ (arrangement angle) was used. The increase of the height of the RAE under shear is expressed by $\Delta h_{1}$ and $\Delta h_{2}$. In fact, the shear dilation area is induced by the height increase in a two-dimensional model, just as shown in Figure 7.

As shown in Figure 7, the area $\left(A_{\alpha}\right)$ of the RAE for any $\alpha$ can be expressed in a general form as $A_{\alpha}=6 R \times 6 R \sin \alpha=$ $36 R^{2} \sin \alpha$, where $R$ is the radius of solid grains and $\alpha$ is the arrangement angle, $60^{\circ} \leq \alpha \leq 90^{\circ}$. Let $\alpha=60^{\circ}$, and the minimum area can be written as $A_{\text {min }}=36 R^{2} \sin 60^{\circ}=18$ $\sqrt{3} R^{2}$; let $\alpha=90^{\circ}$, and the maximum area can be written as $A_{\text {max }}=36 R^{2} \sin 90^{\circ}=36 R^{2}$. The total area $\left(A_{\mathrm{s}}\right)$ of all solid grains is $A_{s}=9 \pi R^{2}$. If the initial arrangement angle changes from $\alpha_{0}$ to $\alpha$ due to shear dilation, the current SDC can be expressed as

$$
\mathrm{SDC}=\frac{\sin \alpha-\sin \alpha_{0}}{\sin \alpha_{0}}
$$

If the initial arrangement angle for an oil sand reservoir is $\alpha_{\mathfrak{i}}$, its SDP is

$$
\mathrm{SDP}=\frac{1-\sin \alpha_{\mathrm{i}}}{\sin \alpha_{\mathrm{i}}}
$$

The porosity for any $\alpha$ is

$$
\phi_{\alpha}=1-\frac{A_{\mathrm{s}}}{A_{\alpha}}=1-\frac{\pi}{4 \sin \alpha} .
$$

The following expression developed by Tortike and Farouq Ali [35] describes a relationship between volumetric strains and absolute permeability:

$$
\frac{k}{k_{0}}=\frac{\left(1+\left(\varepsilon_{\mathrm{v}} / \phi_{0}\right)\right)^{3}}{1+\varepsilon_{\mathrm{v}}},
$$

where $\varepsilon_{\mathrm{v}}$ is the volumetric strain (the thickness is viewed as 1 in the $2 \mathrm{D}$ model) and $\phi_{0}$ is the initial porosity. The porosity variation of oil sand materials as a function of volumetric strain is [36]

$$
\phi=\frac{\phi_{0}+\varepsilon_{\mathrm{v}}}{1+\varepsilon_{\mathrm{v}}} .
$$

Writing the $\varepsilon_{\mathrm{v}}$ as a function of $\phi$ and $\phi_{0}$ according to equation (9), and substituting it into equation (8), equation (8) can also be exhibited as

$$
\frac{k}{k_{0}}=\left(\frac{\phi}{\phi_{0}}\right)^{3}\left(\frac{1-\phi_{0}}{1-\phi}\right)^{2} .
$$

If the initial arrangement angle changes from $\alpha_{0}$ to $\alpha$ due to shear dilation, the permeability improvement capability can be expressed as

$$
\frac{k}{k_{0}}=\left(\frac{4 \sin \alpha-\pi}{4 \sin \alpha_{0}-\pi}\right)^{3} \frac{\sin \alpha_{0}}{\sin \alpha} .
$$

If the initial arrangement angle for an oil sand reservoir is $\alpha_{\mathrm{i}}$, its permeability improvement potential is

$$
\frac{k_{\max }}{k_{\mathrm{i}}}=\left(\frac{4-\pi}{4 \sin \alpha_{\mathrm{i}}-\pi}\right)^{3} \sin \alpha_{\mathrm{i}} .
$$

The 2D evolutions of the shear dilation and permeability improvement capability/potential are described in Figure 8.

If an oil sand reservoir possesses an average arrangement angle of $60^{\circ}\left(\alpha=60^{\circ}\right)$, how should one evaluate the shear dilation and permeability improvement capability induced by different operations of water injection? The curves of SDC and PIC in Figure 8 show that the shear dilation and permeability improvement capabilities increase with the increase of the arrangement angle (here, the increase of the arrangement angle is induced by water injection, and the relation of the arrangement angle and operations can be derived from the microstructures or volumetric strain before and after shear). The two abilities increase sharply at the beginning of dilation (when $\alpha$ is close to $60^{\circ}$ ), but show little change at the end of dilation (when $\alpha$ is close to $90^{\circ}$ ). The maximum shear dilation and permeability improvement capabilities reach 0.15 and 16.33 , respectively, when the oil sand is adequately disturbed and the arrangement angle is exactly forced to a right angle of $90^{\circ}$ by a perfect operation. These results indicate that the shear dilation effects by water injection are very considerable in terms of porosity (volume change) and permeability.

If there are many oil sand reservoirs and their average arrangement angles are different, how should one evaluate and compare their shear dilation or permeability improvement potentials? The curves of SDP and PIP in Figure 8 exhibit that a lower arrangement angle indicates a higher 


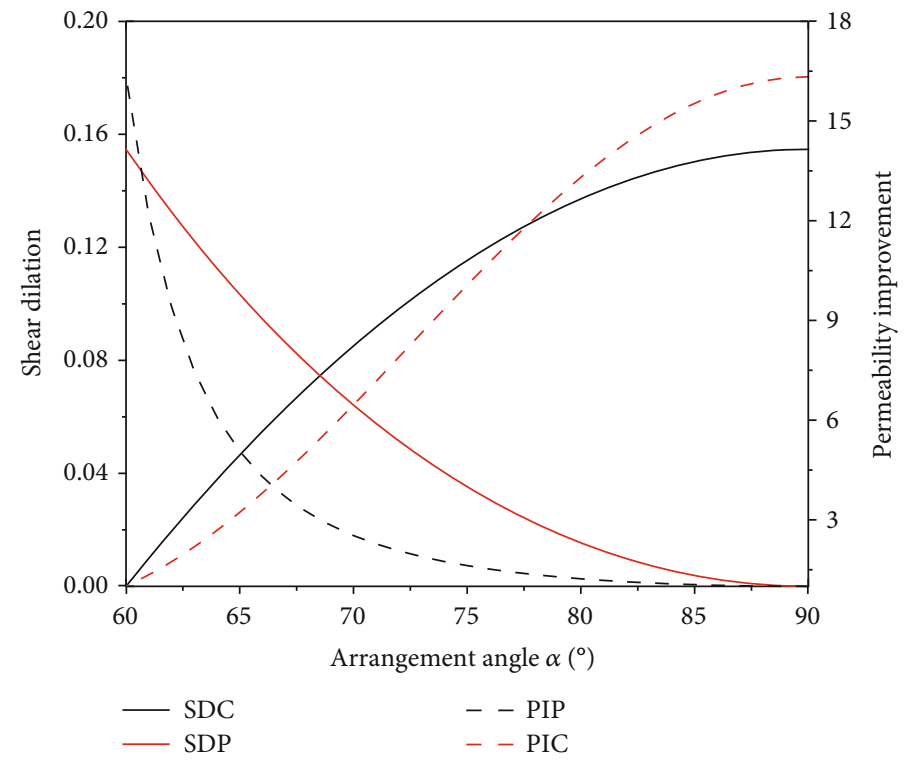

Figure 8: 2D evolutions of the shear dilation and permeability improvement capability/potential.

potential of shear dilation or permeability improvement. If two reservoirs have two different arrangement angles that are both near $60^{\circ}$, their potentials will be very different and even the difference of two arrangement angles is very small. However, when two reservoirs have two different arrangement angles that are both near $90^{\circ}$, there is little difference between the two potentials. The maximum shear dilation and permeability improvement potentials reach 0.15 and 16.33, respectively, when a reservoir possesses a virgin arrangement angle of $60^{\circ}$. These results tell us that a reservoir with a lower arrangement angle will have a higher potential of shear dilation and permeability increase. It is noted that the capability and potential in this study are the same because the selected arrangement angle $\left(\alpha_{0}\right)$ used for the analyses of capability is $60^{\circ}$. The capability and potential will be different when $\alpha_{0} \neq 60^{\circ}$.

3.2. Three-Dimensional Model. Water injection into reservoirs can lead to the shear dilation not only in a plane perpendicular to the borehole axis but also in the direction of the wellbore extension if the injection is uneven along the well. In this regard, a three-dimensional shear is more reasonable in the field practice. The three-dimensional model is a general form of shear dilation, and it can be reduced to a two-dimensional model if the shear dilation in the direction of the wellbore extension is neglected. Twenty-seven oil sand grains were used for forming the representative volume element (RVE). Basic assumptions in this model are the same with the two-dimensional model. The three-dimensional shear dilation behaviors can be displayed as shown in Figure 9.

In this paper, the shear dilation was assumed to occur in two orthonormal directions (in a complex operation of water injection, it is hard to say what the two directions of shear dilation are, but the condition shown in Figure 9 is a most possible and effective type). For easily understanding the shear dilation mechanism, a projection to a direction was drawn to show the particle packing state, and the projection to another direction was the same. All spheres in this model are with the same radius of $R$. The oil sand grain distributions are characterized by two arrangement angles $\alpha$ and $\beta$ $\left(60^{\circ} \leq \alpha \leq 90^{\circ}, 60^{\circ} \leq \beta \leq 90^{\circ}\right)$. The shear dilation volume can also be embodied by the expansions in two directions. In Figure $9, \Delta h_{11}$ and $\Delta h_{12}$ are the vertical expansions, and $\Delta$ $h_{21}$ and $\Delta h_{22}$ are the horizontal expansions.

The total volume of all round solid grains is $V_{\mathrm{s}}=27 \times$ $(4 / 3) \pi R^{3}=36 \pi R^{3}$. If the shear stresses in two directions are different, the relation of the two arrangement angles is $\alpha \neq$ $\beta$. However, this situation makes it hard to calculate the volume after dilation. In this paper, the two angles were viewed as two approximate values, and $\alpha$ was viewed as a mean value of the two angles in two directions. Using the particle packing method, the volume of the RVE $\left(V_{\alpha}\right)$ can be expressed in a general form as follows [37]:

$$
V_{\alpha}=216 R^{3}(1-\cos \alpha) \sqrt{1+2 \cos \alpha}
$$

If the initial arrangement angle changes from $\alpha_{0}$ to $\alpha$ due to shear dilation, the SDC can be expressed as

$\mathrm{SDC}=\frac{(1-\cos \alpha) \sqrt{1+2 \cos \alpha}-\left(1-\cos \alpha_{0}\right) \sqrt{1+2 \cos \alpha_{0}}}{\left(1-\cos \alpha_{0}\right) \sqrt{1+2 \cos \alpha_{0}}}$

If the initial arrangement angle for an oil sand reservoir is $\alpha_{\mathrm{i}}$, its SDP is

$$
\operatorname{SDP}=\frac{1-\left(1-\cos \alpha_{\mathrm{i}}\right) \sqrt{1+2 \cos \alpha_{\mathrm{i}}}}{\left(1-\cos \alpha_{\mathrm{i}}\right) \sqrt{1+2 \cos \alpha_{\mathrm{i}}}}
$$




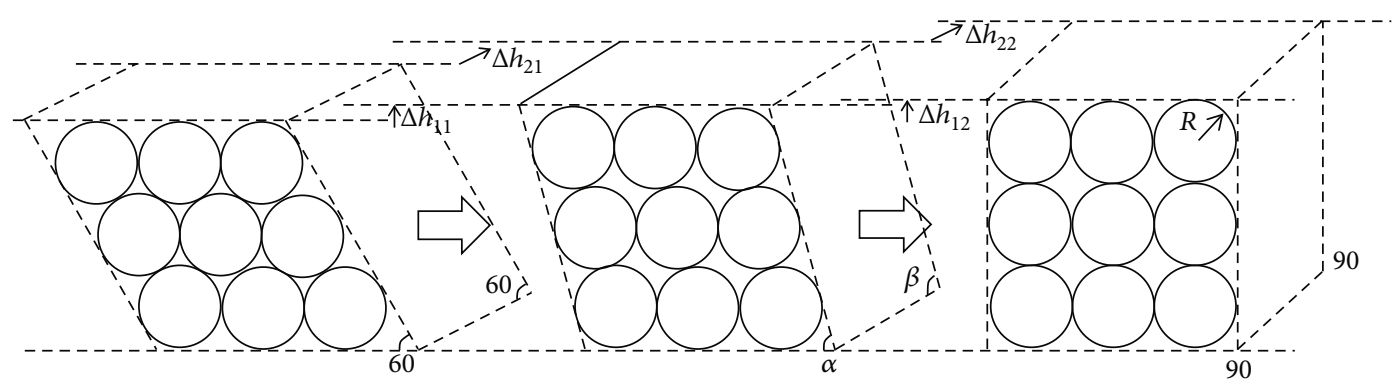

(a)

(b)

(c)

Figure 9: 3D evolutions of the shear dilation and permeability improvement capability/potential.

The porosity is

$$
\begin{aligned}
\phi_{\alpha} & =1-\frac{36 \pi R^{3}}{216 R^{3}(1-\cos \alpha) \sqrt{1+2 \cos \alpha}} \\
& =1-\frac{\pi}{6(1-\cos \alpha) \sqrt{1+2 \cos \alpha}} .
\end{aligned}
$$

According to equation (10), if the initial arrangement angle changes from $\alpha_{0}$ to $\alpha$ due to shear dilation, the permeability improvement capability can be obtained by

$$
\begin{aligned}
\frac{k}{k_{0}}= & {\left[\frac{6(1-\cos \alpha) \sqrt{1+2 \cos \alpha}-\pi}{6\left(1-\cos \alpha_{0}\right) \sqrt{1+2 \cos \alpha_{0}}-\pi}\right]^{3} } \\
& \cdot \frac{1-\cos \alpha_{0}}{1-\cos \alpha} \sqrt{\frac{1+2 \cos \alpha_{0}}{1+2 \cos \alpha}}
\end{aligned}
$$

If the initial arrangement angle for an oil sand reservoir is $\alpha_{\mathrm{i}}$, its permeability improvement potential is

$$
\begin{aligned}
\frac{k_{\max }}{k_{\mathrm{i}}}= & {\left[\frac{6-\pi}{6\left(1-\cos \alpha_{\mathrm{i}}\right) \sqrt{1+2 \cos \alpha_{\mathrm{i}}}-\pi}\right]^{3} } \\
& \cdot\left(1-\cos \alpha_{\mathrm{i}}\right) \sqrt{1+2 \cos \alpha_{\mathrm{i}}} .
\end{aligned}
$$

The three-dimensional evolutions of the shear dilation and permeability improvement capability/potential are described in Figure 10.

As shown in Figure 10, the tendencies of the shear dilation and permeability improvement capability/potential of the $3 \mathrm{D}$ model are identical with those of the $2 \mathrm{D}$ model. However, the predicted shear dilation potential by the $3 \mathrm{D}$ model is a lot higher than that by the $2 \mathrm{D}$ model; the predicted permeability improvement potential by the $3 \mathrm{D}$ model is lower than that by the $2 \mathrm{D}$ model. The curves of SDC and PIC in Figure 10 show that the SDC and PIC increase with the increase in the arrangement angle induced by favorable operations of water injection for the oil sand reservoir possessing an average arrangement angle of $60^{\circ}$. The maximum shear dilation and permeability improvement capabilities reach 0.41 and 12.37, respectively, when the oil sand reservoir is adequately disturbed and the two arrangement angles are exactly forced to two right angles of $90^{\circ}$ by a perfect operation. These results indicate that the shear dilation effects by water injections are very considerable in terms of porosity and permeability. The SDC prediction result of this model is much higher than that of the 2D model, while the PIC in this model is a little lower than that of the 2D model. The curves of SDP and PIP exhibited in Figure 10 show that a reservoir with a lower average arrangement angle has a higher potential of shear dilation and permeability increase. The maximum shear dilation and permeability improvement potentials in this model reach 0.41 and 12.37, respectively, when a reservoir possesses a virgin arrangement angle of $60^{\circ}$.

\section{Model Validation}

4.1. Triaxial Compression and Permeability Test Results of Karamay Oil Sands. A high-pressure and high-temperature triaxial test system integrated with a pulse-decay permeability test apparatus (GCTS RTR-1500, Figure 11) was used to investigate the mechanical behaviors of Karamay oil sands under shear, aiming to validate the models proposed in this paper. The oil sand samples (vertical regular oil sands) with a size of $25 \mathrm{~mm} \times 50 \mathrm{~mm}$ (diameter $\times$ length) were tested under triaxial drained compression until yielded, so as to study the different mechanical responses under varying effective confining stresses and temperatures (corresponding to actual reservoir conditions under water injection).

In these experiments, the shear behaviors of specimens were tested at some effective confining stresses of $0.5,1,2$, and $5 \mathrm{MPa}$, respectively (by controlling the confining stresses as $5.5,6,7$, and $10 \mathrm{MPa}$, respectively, under a constant pore pressure of $5 \mathrm{MPa}$ ). A vertical loading velocity of $0.03 \mathrm{~mm} / \mathrm{min}$ was adopted until the axial strain reached $9 \%$. These tests were conducted at 20,45 , and $70^{\circ} \mathrm{C}$, respectively. The permeabilities of most of the specimens were measured before and after shear. The axial strain-deviatoric stress curves and axial strain-volumetric strain curves are shown in Figures 12(a) and 12(b), respectively. In this paper, the curves of test results at the effective confining stresses of 1 and $2 \mathrm{MPa}$ and at room temperature were not given for simplicity, and they can be found in the literature [8]. The tested permeability data is shown in Figure 3, and the permeability improvement induced by shear dilation is calculated and shown in Table 2.

4.2. Comparison of Theoretical Models and Test Data. To validate the theoretical models, the experimental data exhibited 


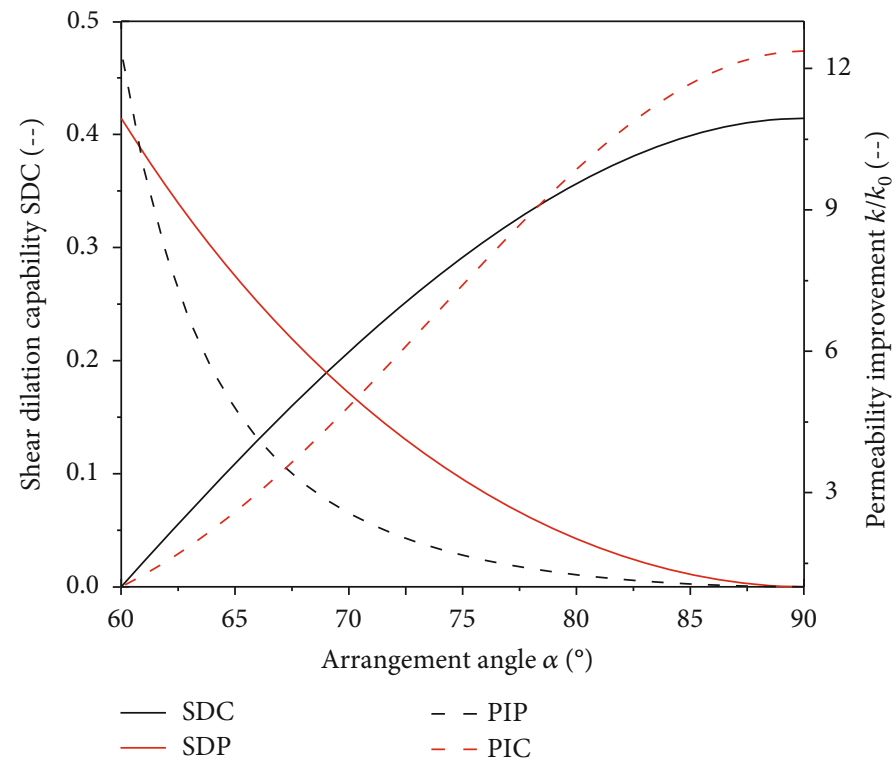

FIGURE 10: 3D evolutions of the shear dilation and permeability improvement capability/potential.

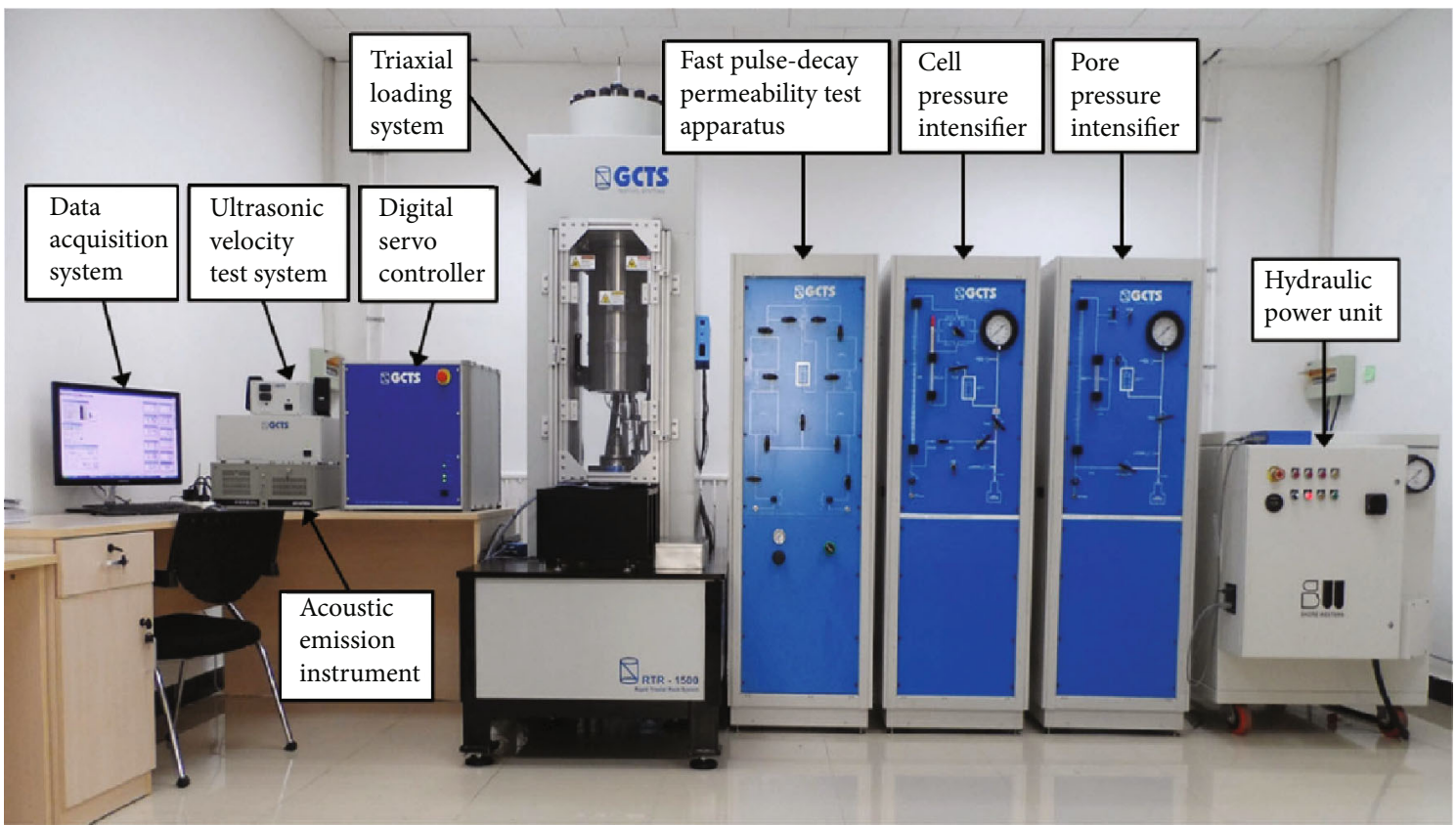

FIGURE 11: High-pressure and high-temperature triaxial test system integrated with pulse-decay permeability test apparatus.

above was used to compare with the predicted results shown in Figures 8 and 10. Both the SDC and PIC derived from experiments and models were compared, respectively. For the RAE in Figure 7, compression and expansion occur in the horizontal and vertical directions, respectively. Therefore, the horizontal direction in Figure 6 is corresponding to the axial direction of the specimens in the experiment, and the relation of axial strain and alpha of the $2 \mathrm{D}$ model for a RAE with $3 \times 3$ grains is

$$
\varepsilon_{\mathrm{a}}=\frac{8 R-(6 R+4 R \cos \alpha)}{8 R} .
$$

In general, the relation of the axial strain and alpha of a $2 \mathrm{D}$ model for a RAE with $n \times n$ grains is

$$
\varepsilon_{\mathrm{a}}=\frac{(n-1) R-2(n-1) R \cos \alpha}{(3 n-1) R} .
$$

When the RAE is large enough $(n \rightarrow \infty)$, there is

$$
\varepsilon_{\mathrm{a}}=\lim _{n \rightarrow \infty} \frac{(n-1) R-2(n-1) R \cos \alpha}{(3 n-1) R}=\frac{1}{3}-\frac{2}{3} \cos \alpha .
$$




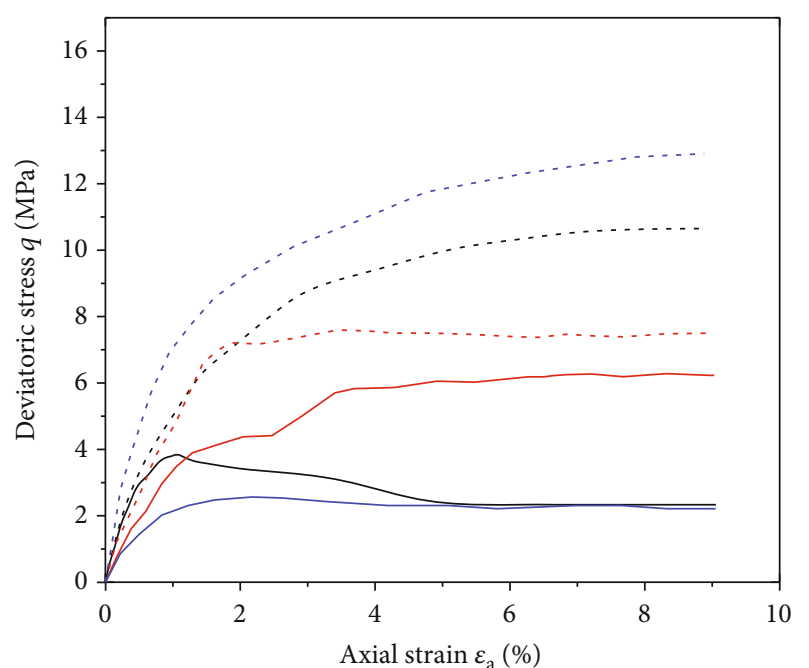

$\begin{array}{rrr}20^{\circ} \mathrm{C}, 0.5 \mathrm{MPa} & \ldots \ldots & 20^{\circ} \mathrm{C}, 5 \mathrm{MPa} \\ -45^{\circ} \mathrm{C}, 0.5 \mathrm{MPa} & \ldots \ldots & 45^{\circ} \mathrm{C}, 5 \mathrm{MPa} \\ -70^{\circ} \mathrm{C}, 0.5 \mathrm{MPa} & \ldots \ldots & 70^{\circ} \mathrm{C}, 5 \mathrm{MPa}\end{array}$

(a)

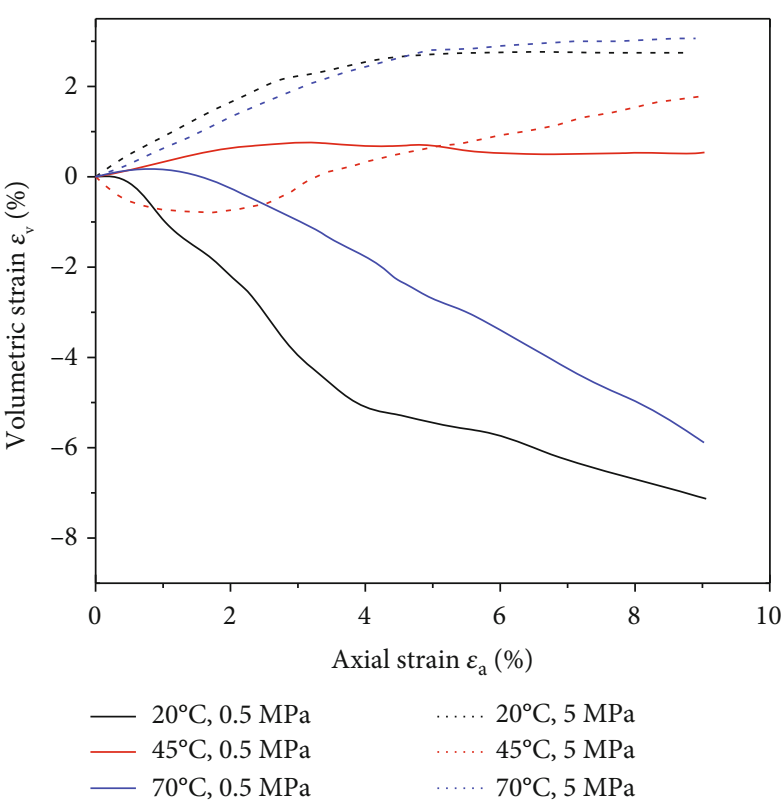

(b)

Figure 12: Axial strain-deviatoric stress curves and axial strain-volumetric strain curves under varying effective confining stresses and temperatures [8].

TABLe 2: Permeability changes of oil sands before and after shear.

\begin{tabular}{lcccc}
\hline Temperature $\left({ }^{\circ} \mathrm{C}\right)$ & $\begin{array}{c}\text { Effective confining } \\
\text { stress }(\mathrm{MPa})\end{array}$ & $k_{0}(\mu \mathrm{D})$ & $k(\mu \mathrm{D})$ & $\mathrm{PIC}$ \\
\hline \multirow{3}{*}{20} & 0.5 & & 5996 & 2.08 \\
& 1 & 2886 & 4866 & 1.69 \\
& 2 & & 3144 & 1.09 \\
& 5 & & 1996 & 0.69 \\
\hline \multirow{2}{*}{70} & 0.5 & 2886 & 5274 & 1.83 \\
& 5 & & 1663 & 0.58 \\
\hline
\end{tabular}

The relation of the axial strain and alpha for a 3D model is too hard to derive, and these obscure derivations were shown in the study of Scott [37]. For simplicity, equation (21) was used to approximately express the relation of the axial strain and alpha for the 3D model.

In these experiments, the maximum shear dilation occurred at $20^{\circ} \mathrm{C}$ and at a low effective confining stress of $0.5 \mathrm{MPa}$. The theoretical models proposed in Section 3 were used to fit the experimental axial strain-volumetric strain curves. As shown in Figure 13, the SDC predicted by the models agrees well with the experimental data. There are four curves fitting the experimental data. The $2 \mathrm{D}$ model can well fit the shear dilation-induced volumetric expansion, no matter what size the RAE is (the size of RAE in this paper is $3 \times 3$, and $n \times n$ is a perfect situation). The predicted results of the $3 \mathrm{D}$ models are not very good, because the relation of the axial strain and alpha for the 3D models is just approximately estimated according to the $2 \mathrm{D}$ models. The half-value of the predicted results of original 3D models seems to fit well with the experimental data.

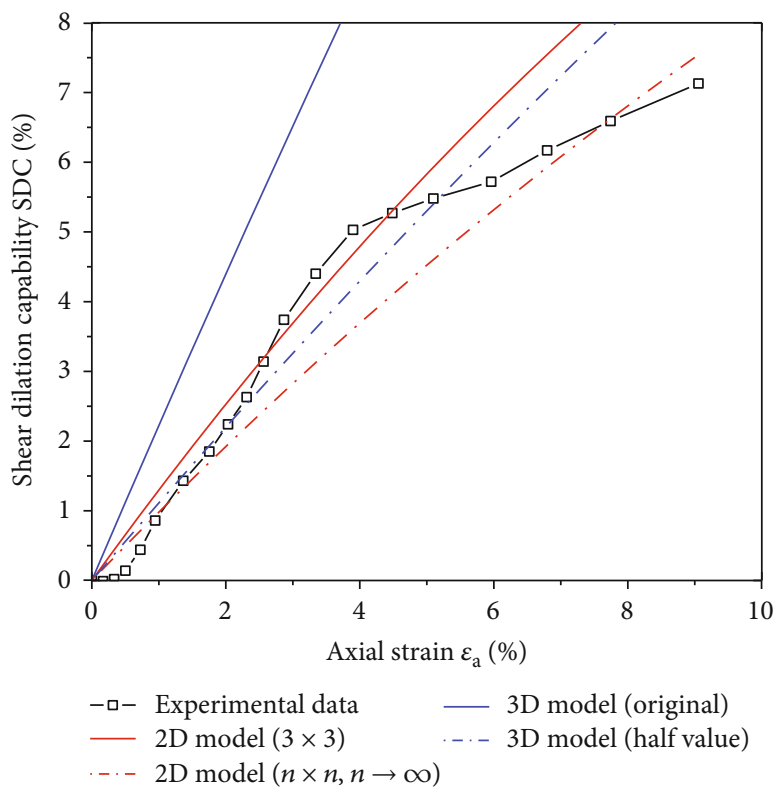

FIGURE 13: Curve fitting of experimental axial strain-SDC curves by proposed theoretical models.

When bitumen is immobile, it is impossible to measure the absolute permeability of oil sands, so the absolute permeability by experiments and theoretical models cannot be directly compared. In this condition, the effective permeability to water after shear dilation measured by experiments was used to indirectly validate the theoretical models. In these experiments, the ultimate axial strain was $9 \%$, so the alpha in the theoretical models was $68.59^{\circ}$ according to equation (21). The PICs evaluated by $2 \mathrm{D}$ and $3 \mathrm{D}$ models were 5.4 


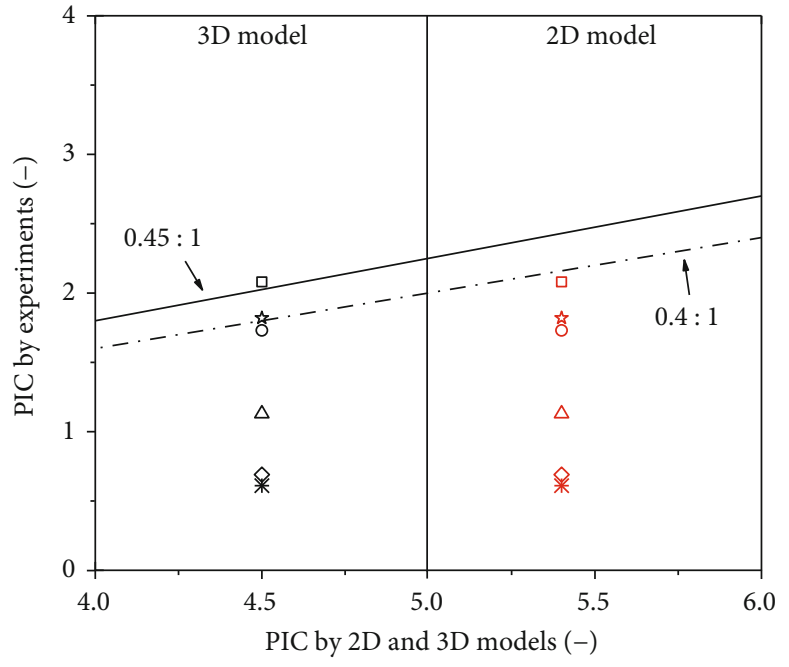

$20^{\circ} \mathrm{C}, 0.5 \mathrm{MPa} \quad \circ 20^{\circ} \mathrm{C}, 1 \mathrm{MPa} \quad \square 20^{\circ} \mathrm{C}, 0.5 \mathrm{MPa} \quad 020^{\circ} \mathrm{C}, 1 \mathrm{MPa}$

$\triangle 20^{\circ} \mathrm{C}, 2 \mathrm{MPa} \diamond 20^{\circ} \mathrm{C}, 5 \mathrm{MPa} \triangle 20^{\circ} \mathrm{C}, 2 \mathrm{MPa} \diamond 20^{\circ} \mathrm{C}, 5 \mathrm{MPa}$

\& $70^{\circ} \mathrm{C}, 0.5 \mathrm{MPa} * 70^{\circ} \mathrm{C}, 5 \mathrm{MPa}$ क $70^{\circ} \mathrm{C}, 0.5 \mathrm{MPa}$ * $20^{\circ} \mathrm{C}, 0.5 \mathrm{MPa}$

FIgURE 14: Comparison of PICs predicted by experimental and theoretical models (when the axial strain is $9 \%$ ).

and 4.5, respectively. The PICs in Table 2 are plotted in Figure 14. It is worth noting that the permeability tested by experiments is effective permeability to water, but the permeability predicted by theoretical models is absolute permeability. The effective permeability to water is lower than the absolute permeability, and it is related with the water saturation and distribution. Besides, the ideal value for the actual absolute permeability after shear dilation is hard to reach if calculated by $2 \mathrm{D}$ and $3 \mathrm{D}$ models. In this paper, two straight lines of $0.45: 1$ and $0.4: 1$ were used to fit the experimental data. If the data lands on straight lines, it means that the actual PICs by the present experiments can only reach 0.45 or 0.4 times that of the ideal models. From Figure 14, it can be seen that the PIC under the best shear dilation (when the effective confining stress is $0.5 \mathrm{MPa}$ and temperature is $20^{\circ} \mathrm{C}$ ) can reach 0.45 times of the ideal $3 \mathrm{D}$ model and 0.4 times of the ideal 2D model.

4.3. Model Corrections by Coordination Number. As discussed in Section 4.2, the actual SDC and PIC measured by experiments are always lower than those predicted by theoretical methods. It is because the grain contacts in the actual oil sand reservoir are not as sufficient as what is described in the ideal model. To make the models more coincidental to actual situations, the coordination number for an actual particle packing body was used to correct the previous model.

The Karamay terrestrial oil sand possesses a very loose structure because of the absence of glacial compaction. The presence of lots of intergranular fillers (including highly viscous bitumen) depresses the possibility of grain contacts, so the shear dilation potential of the Karamay oil sand is not as good as that of the Canadian marine oil sand under the same improved artificial operations. But the breccia-shaped
Karamay oil sand grains have sharp edges and form an interlocked structure, which indicates a high shear dilation potential if these grains can contact each other after some adequate measures such as decreasing the viscosity of bitumen and increasing the mean effective stress. Figure 15 shows the microstructures of Karamay and Athabasca oil sands. The images in Figures 15(d)-15(f) are derived from Dusseault and Morgenstern [4].

The 2- and 3-dimensional models are all ideal models, because the particle packing state is just like in soils where the grains are all in sufficient contact. Although the Karamay oil sands are a kind of unconsolidated sandstones, it is hard to say if any grain is in contact with its adjacent grains, just like what is shown in Figure 16. In this paper, a concept of coordination number $N$ was used to embody the situation of the insufficient contact of particles.

In Figure 16, the particle labeled no. 1 has four particles that contact it by point to point instead of six particles, just like what is shown in Figure 7. The coordination number of the particle labeled 1 was defined as the total number of particles that have a point-to-point contact with this particle labeled 1 . In other words, the $N$ of the particle packing state shown in Figure 12 is 4 . This determination method is both suitable for the $2 \mathrm{D}$ and $3 \mathrm{D}$ models.

Using the coordination number $N$ (average number of contacts), the actual shear dilation and permeability improvement capability/potential can be expressed as follows (here taking the $\mathrm{SDC}_{\text {actual }}$ for an instance):

$$
\mathrm{SDC}_{\text {actual }}=\frac{N-N_{\text {min }}}{N_{\text {max }}-N_{\text {min }}} \times \mathrm{SDC},
$$

where $N_{\max }$ is the maximum coordination number, and it is equal to 6 and 12 for the $2 \mathrm{D}$ and $3 \mathrm{D}$ models, respectively, and $N_{\min }$ is the minimum coordination number, and it is equal to 2 and 6 for the 2D and 3D models, respectively.

The stability of a circle in a plane needs at least two neighboring circles, so the minimum coordination number for a $2 \mathrm{D}$ model is 2 . The minimum coordination number for a $3 \mathrm{D}$ model can be obtained from Figure 17. From equation (22), $N=N_{\max }\left(\right.$ SDC $_{\text {actual }}=$ SDC $)$ means a perfect particle packing state, just like those shown in Figures 7 and 9. There is $\mathrm{SDC}_{\text {actual }}=0$ when $N=N_{\text {min }}$, which is an extreme condition when there is no effective grain contact for sliding.

The volumetric strain by triaxial compression experiments and the injection volume in the field practice are all corresponding to a 3D occasion. However, it is hard to find the coordination number of a 3D model by the ESEM image. In this regard, another approach of determining the average coordination number can be achieved by previous experiments. Smith et al. [38] used five isodiametric particle-packing bodies with different porosities to study the relation of the average porosity and average coordination by experiments:

$$
N=\frac{10.968 \phi-6.527}{0.414(\phi-1)}
$$




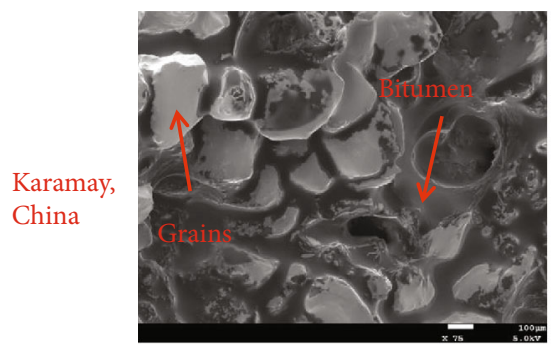

(a)

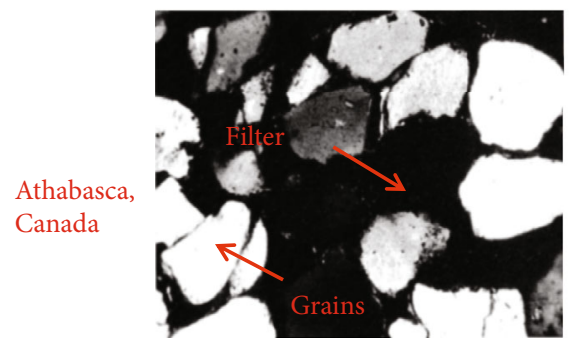

(d)

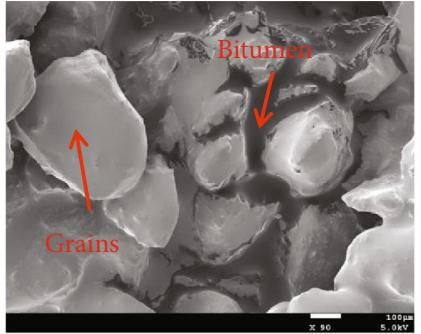

(b)

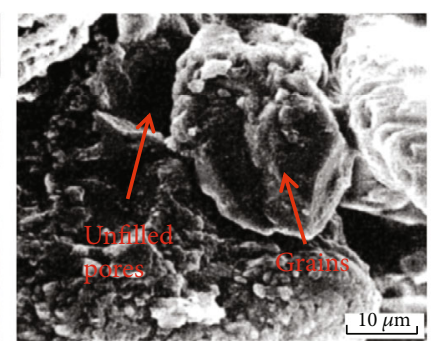

(e)

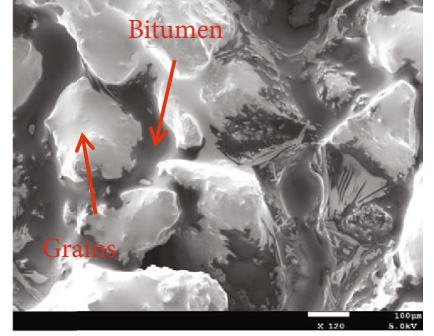

(c)

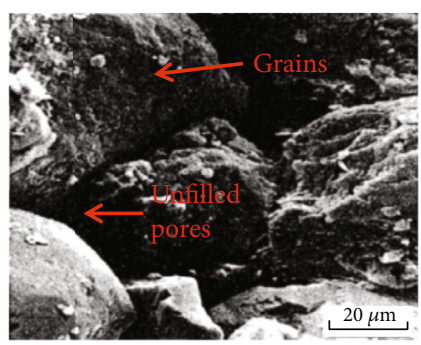

(f)

Figure 15: Microstructure contrast of oil sands in Karamay, China and Athabasca, Canada.

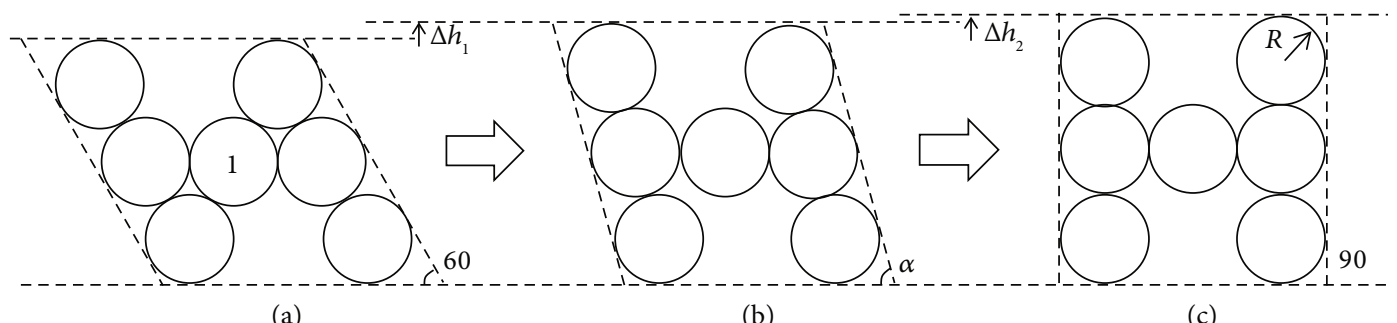

(a)

(b)

(c)

FIGURE 16: Shear dilation of the actual oil sand with insufficient grain contacts.

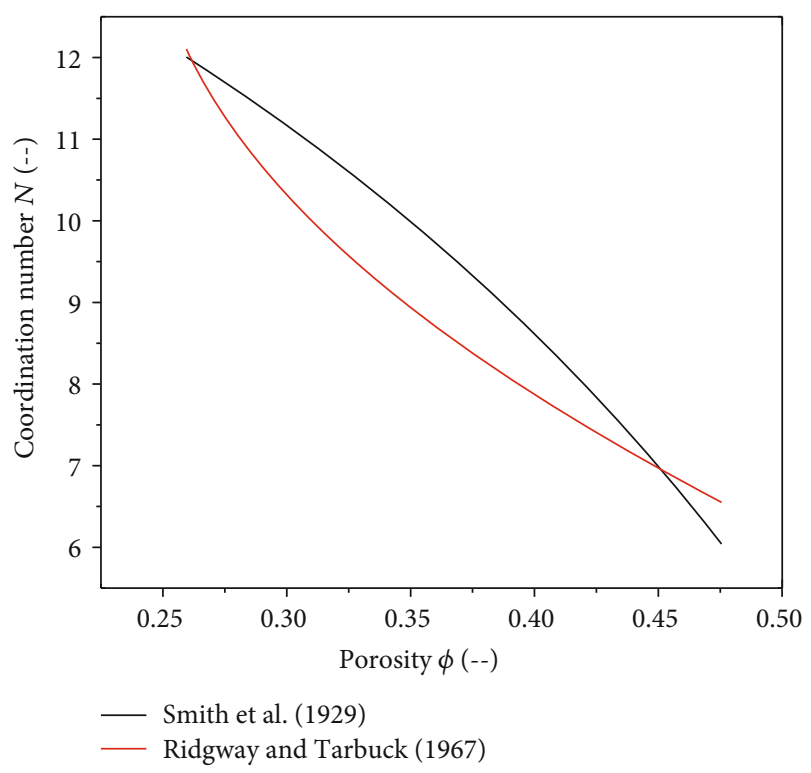

FIGURE 17: Relation of coordination number and porosity for a real oil sand.
Ridgway and Tarbuck [39] also gave the relation between the coordination number and porosity by the least square method:

$$
N=\frac{0.1193-\sqrt{0.01724 \phi-0.00425}}{0.00862}
$$

Therefore, if the porosity of an actual oil sand with insufficient grain contacts is known, the coordination number can be obtained according to Figure 17.

It can be seen from Figure 17 that the prediction results by Smith et al. are a little higher than those by Ridgway et al. in most occasions. A lower porosity always means a higher coordination number. Once the coordination number is obtained, the actual shear dilation effects can be evaluated according to equation (19).

Up to now, the mathematical relations of the arrangement angle and shear dilation/permeability improvement have been discussed. However, how to apply these curves into field practices for engineers needs more practical information (e.g., the injection data, triaxial expression experiments, and microstructure images). The end significance of this paper is to find the shear dilation effects quantitatively 
represented by SDC and PIC under actual field operations, and to see how much residual effective shear dilation potentials quantitatively described by SDP and PIP are for further utilization. Next, the evaluation procedures and several case studies will be given.

\section{Field Applications}

Wellpair A-2 in Karamay corresponds to a recently stimulated reservoir in area A. The vertical depths of the I (injection) and P (production) wells recorded $367 \mathrm{~m}$ and $372 \mathrm{~m}$, respectively. The thickness of the reservoir is $20.5 \mathrm{~m}$. The horizontal section of the wellpair was designed to be $500 \mathrm{~m}$ in length. Laboratory results revealed that the oil sand sample has a water content of $1.8 \%$, a bitumen content of $8.7 \%$, a fines content of $9.2 \%$, a porosity (excluding bitumen) of $16.6 \%$, and an effective permeability to water $k_{\mathrm{w} 0}=882 \mu \mathrm{D}$ in the vertical direction (a lateral ratio of 0.5 was used to obtain the horizontal permeability). There are enough oil sand cores for conducting the ESEM/triaxial compression tests and lots of field operation data including the injection rate and pressure provided by the Fengcheng oilfield.

This paper provided a method of evaluating the shear dilation and permeability improvement capability/potential by microstructures derived from the ESEM images. Previous studies in this paper were concentrated on the dilation by shear, and the tensile parting dilation was not discussed. However, it is also important for field engineers to evaluate the total dilation effects by macroscale like the triaxial compression experiments and field injection information. In this regard, the total dilation and permeability improvement capability/potential can be defined when the current volumes and permeabilities in equations (1)-(4) are induced by both shear and tensile parting dilation instead of just by shear dilation. Therefore, the relation of the shear and total dilation capability is

$$
\mathrm{DC}=\mathrm{SDC}+\mathrm{TPDC},
$$

where DC is the total dilation capability and TPDC is the tensile parting dilation capability. Another three related definitions also have the form just like equation (25). This paper provided a case study of evaluating the shear dilation and permeability improvement potentials by the microstructures derived from the ESEM images. The evaluated results by the triaxial drained tests and field information were also discussed for comparison.

5.1. Microstructures of Karamay Oil Sands. Figure 18 gives an image of the Karamay oil sand microstructure by ESEM experiments. According to the evaluation procedures, the arrangement angle $\alpha_{\mathrm{i}}$ can be obtained as $\alpha_{\mathrm{i}}=65^{\circ}$ (here, we suppose that $\alpha_{\mathrm{i} 1}, \alpha_{\mathrm{i} 2}, \cdots, \alpha_{\mathrm{in}}$ are all close to $\alpha_{\mathrm{i}}$, and $\alpha_{\mathrm{i}}$ is a mean value). From the curves of SDP and PIP in Figure 10 (3D condition), the shear dilation and permeability improvement potentials are about 0.27 and 4.8 , respectively. It is worth noting that the coordination number by a $2 \mathrm{D}$ image can only embody the microstructure in a plane, so it is hard to represent a reservoir with a strong heterogeneity. In this regard, the coordination number in a $3 \mathrm{D}$ model can be evaluated by the porosity. The porosity was tested as 0.33 (by porosity experiments shown in Table 1), so the coordination number is 9 (by Ridgway et al. in Figure 17) and the actual shear dilation and permeability improvement potentials are $(9-$ $6) /(12-6) \times 0.27=0.135$ and $(9-6) /(12-6) \times 4.8=2.4$, respectively. The permeability after shear can reach 2.4 times that of the initial permeability, namely $2116.8 \mu \mathrm{D}$, which is much more favorable for subsequent steam circulation and oil production.

5.2. Volumetric Strain Curves. In Section 4, the laboratory triaxial drained compression experiments for cylindrical standard cores of $25 \mathrm{~mm} \times 50 \mathrm{~mm}$ (diameter $\times$ length) under the stress conditions corresponding to the actual underground stress state were employed to simulate and evaluate the stress-strain responses and dilation behaviors. Because the pore pressure during the experiment was kept constant, the tensile parting dilation made no contribution to the total deformation. Here, the curves of the axial strain vs. volumetric strain are exhibited in Figure 12(b). It is worth noting that the volumetric strain in these curves is the shear dilation capability. Their relation can be expressed as

$$
\mathrm{SDC}=-\varepsilon_{\mathrm{v}}
$$

From Figure 12(b), the maximum volumetric dilation reaches -0.07 (a negative value means volumetric dilation) under an effective confining stress of $0.5 \mathrm{MPa}$ when the axial strain is about $9 \%$. According to equation (26), the current dilation capability is only 0.07 , and there is about $0.135-$ $0.07=0.065$ dilation potential left for further utilization.

5.3. Field Injection Information. In field practice, injection data including the injection rate $Q$, pressure $P$, and time $t$ are very useful for engineers to predict some information of the underground reservoir. In this study, the cumulative injection volume $V_{\text {inj }}=\int_{0}^{t} Q(t) d t$ was adopted for analyses. In the dilation process (both the shear and tensile parting dilations exist), the increased pore is occupied by the injected water. That is to say, this study can evaluate the dilationinduced increased pore space by calculating the cumulative injection volume [7]. So the total dilation capability (DC) and cumulative injection volume have following relation:

$$
\mathrm{DC}=\frac{V-V_{0}}{V_{0}}=\frac{V_{\mathrm{inj}}}{V_{0}} .
$$

As shown in equation (27), the prediction result of DC is very dependent upon $V_{0}$. If the well length is known, $V_{0}$ is a function of the effective dilation area, which is a semiellipse plane perpendicular to the borehole axis [3, 40-42].

As shown in Figure $19, R_{\mathrm{a}}$ and $R_{\mathrm{b}}$ are the vertical and horizontal effective dilation radii, respectively. Here, for model simplicity, let $R_{\mathrm{a}} \approx R_{\mathrm{b}}=R$. So, equation (27) can be also written as

$$
\mathrm{DC}==\frac{2 V_{\mathrm{inj}}}{\pi R^{2} L} .
$$



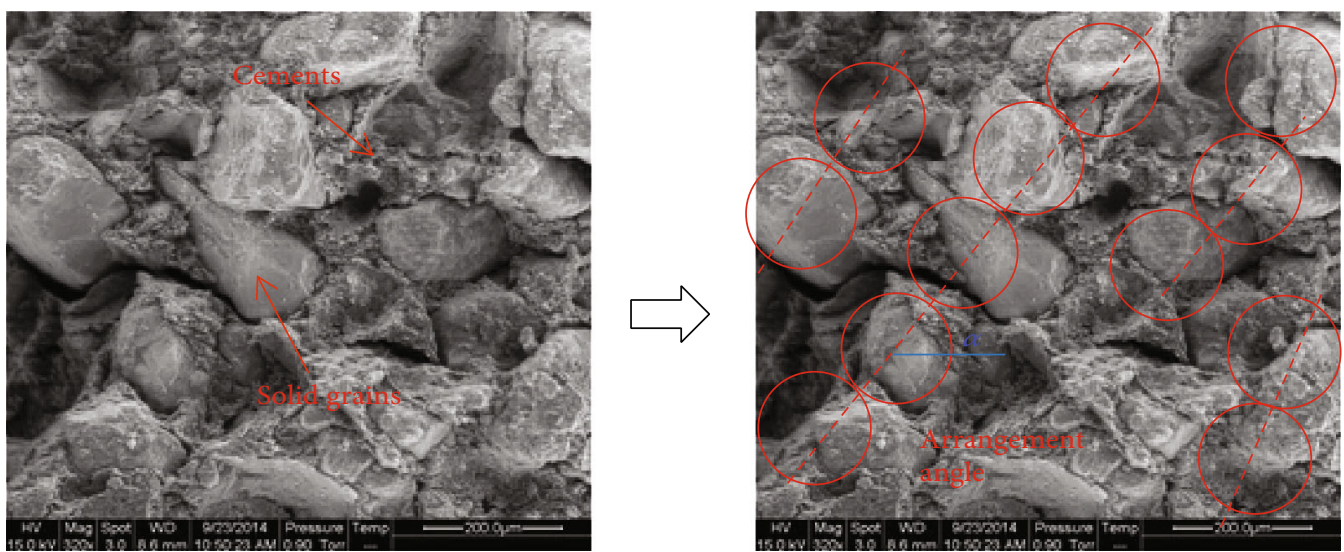

FIGURE 18: Microstructures by the ESEM and methods of obtaining the arrangement angle.

Mud cap rock

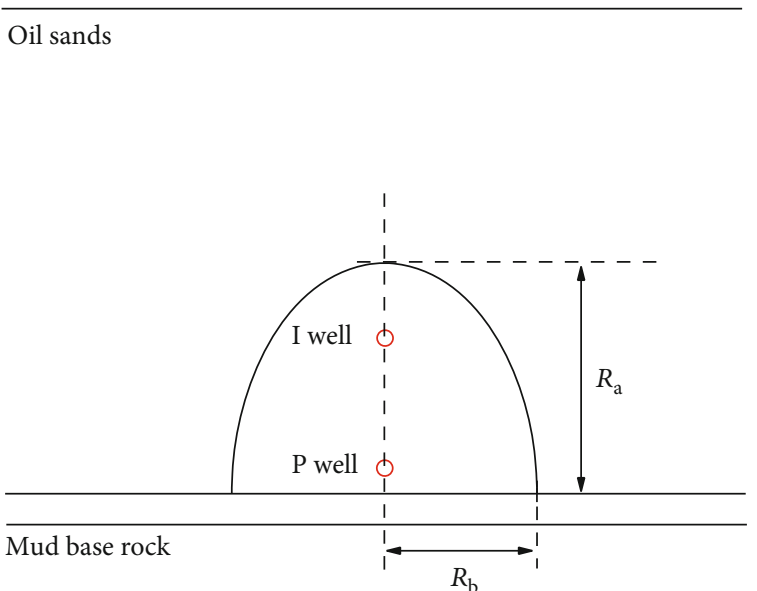

FIGURE 19: Schematic geometry of the hydraulic dilation area in a real oil sand reservoir [42].

The ultimate dilation capability is usually the concern, so the end $V_{\text {inj }}$ is used for calculation. As shown in Figure 20, the total cumulative injection volume of the I and P wells is about $100+125=225 \mathrm{~m}^{3}$.

In this regard, the relation of DC and $R$ can be plotted as shown in Figure 21. The current dilation capability evaluated by the cumulative injection volume drops with the selected effective dilation radius. Because the distance of the SAGD wells is $5 \mathrm{~m}$, the effective dilation radius is impossible to be a value of less than $5 \mathrm{~m}$ at the end of injection. In fact, even for a minimum $V_{0}$, the current dilation capability predicted by the injection data is as low as 0.012 . It is much lower than the predicted result by the microstructure and the laboratory triaxial compression experiments. This tells us that the dilation potential in the Karamay oil sand reservoir is difficult to be efficiently utilized.

Here, the predicted dilation capabilities evaluated by the microstructure and triaxial compression experiments and field injection information, respectively, are plotted in Figure 22 for comparison. The maximum shear dilation capability (or shear dilation potential) is predicted as 0.135

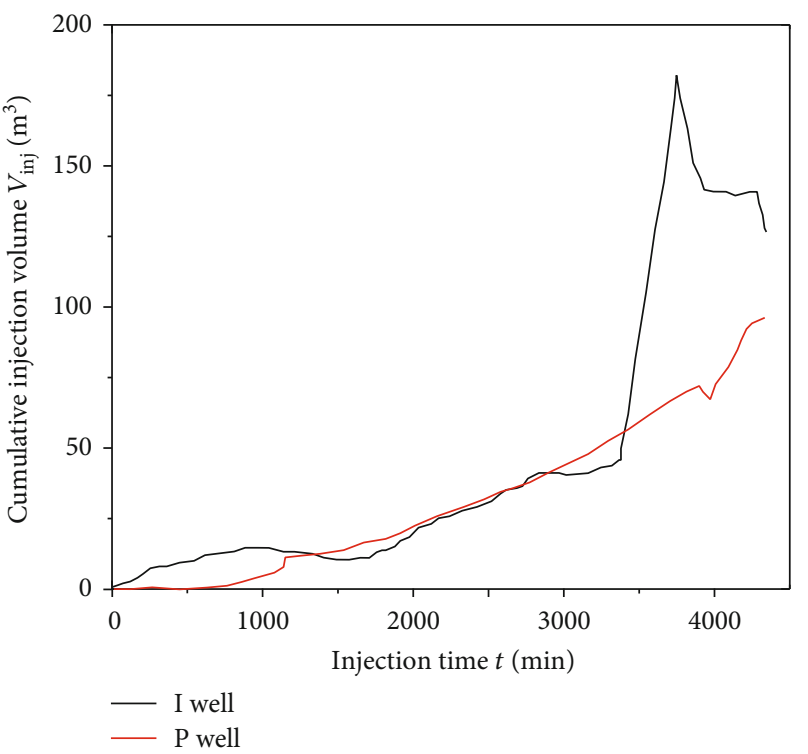

Figure 20: Cumulative injection volume of wellpair A-2.

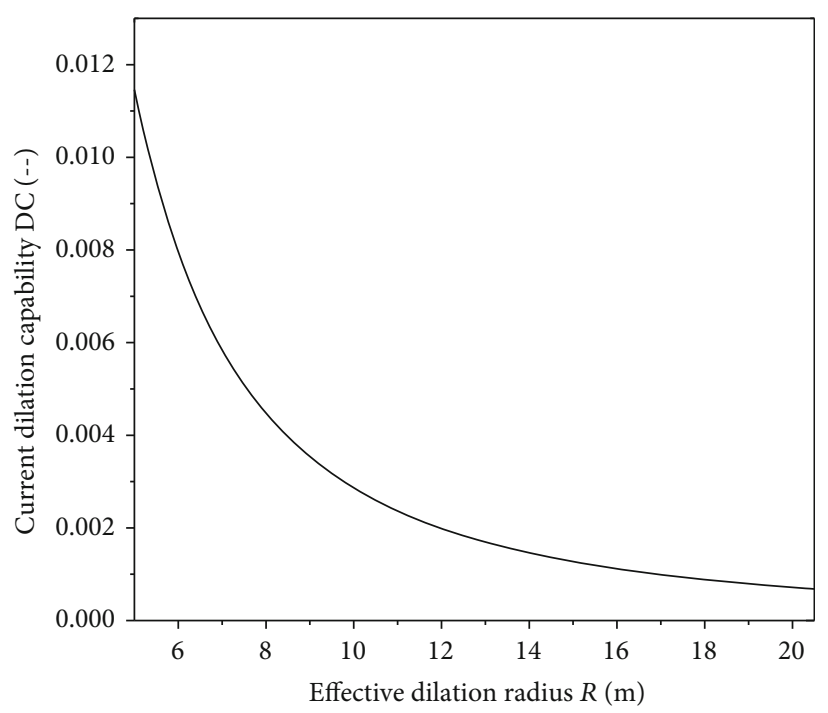

FIGURE 21: Current dilation capability evaluated by injection information. 


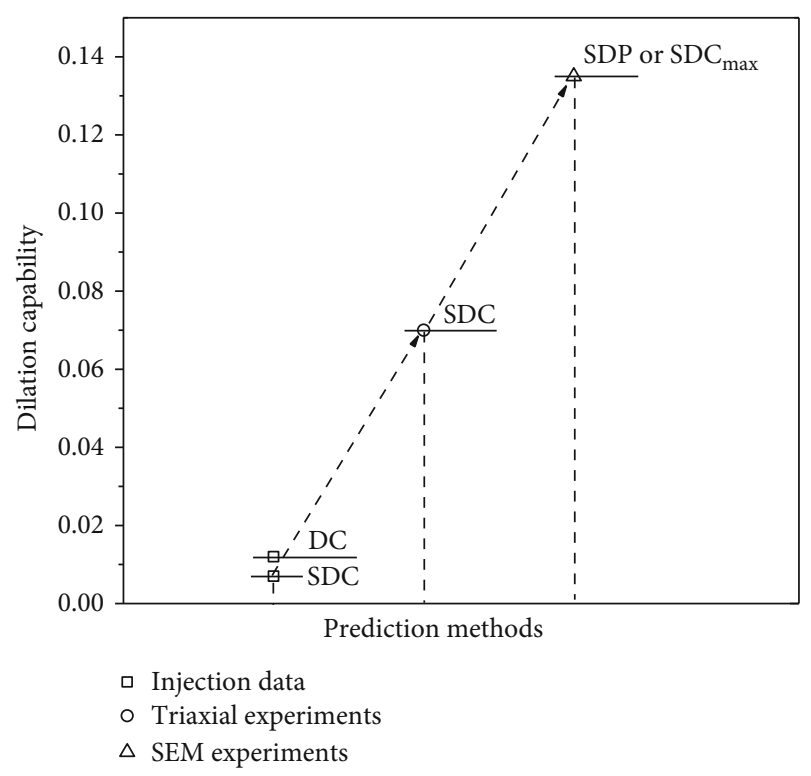

FIGURE 22: Comparison of shear dilation capabilities evaluated by different methods.

by the microstructure derived from the ESEM experiments. The predicted shear dilation capability by the drained triaxial compression experiments is about half of that by the microstructure images. In other words, there is still a shear dilation capability of 0.07 left for further improvement after the geomechanical operations corresponding to the test conditions. The current dilation capability (including both shear and tensile parting shear dilation capability) predicted by the field injection data is about 0.012 , so the shear dilation capability by this method is absolutely less than 0.012 . These findings tell us that the actual (shear) dilation capability is difficult to be used by present field operations, although the oil sand itself has a very high (shear) dilation potential. Therefore, it is desired for the engineers to design adequate measures to efficiently utilize the remaining high dilation potential.

\section{Discussion}

This paper proposed a method of evaluating the shear dilation effects of the Karamay oil sand reservoir under water injection by particle packing theory. Based on the special petrophysical properties of Karamay oil sands, two definitions (e.g., shear dilation and permeability improvement capability/potential) were employed for the quantitative descriptions of the shear dilation effects. According to the microstructures derived from the ESEM experiments, both two-dimensional and three-dimensional evaluation models were established for obtaining the relation of the evaluation parameters and arrangement angles. These models can not only predict the maximum shear dilation capability (potential) and permeability evolutions according to the ESEM images even prior to the artificial operations but also analyze the current shear dilation and permeability improvement effects under water injection by simulating the reservoir deformation derived from the laboratory triaxial compression experiments and detecting the wellhead flow rate.

A number of laboratory experiments and discrete element simulations revealed that the scale effect (i.e., changing the sizes of a particle or specimen) has an important impact on the shear dilation behavior, which can be quantitatively measured by the volumetric strain or the shear band volume. Bolton and Lau [43] demonstrated that the shear dilation of the silica flour with smaller particle sizes is greater than that of the flint grit. Bardet and Proubet [44, 45], Vardoulakis and Graf, and Muhlhaus and Vardoulakis [46, 47] theoretically and experimentally studied the shear band thickness in granular materials. Cai [48] studied the dilation behavior of the dense sand specimens with different sizes by laboratory tests and PFC (particle flow code) simulations and discovered that a relatively smaller standard specimen usually possesses a more obvious dilation behavior (i.e., a wider shear band and a greater volumetric expansion). During the shear process, the specimen can be divided into two regions, i.e., shear dilation region (near the shear bands) and compaction region. For a smaller specimen, the shear dilation region occupies a relatively larger volume ratio, leading to a stronger capability of volumetric expansion [48]. Therefore, the scale effect has an impact on permeability and porosity enhancement due to dilation, because the shear dilation is a local phenomenon within the shear band. The theoretical models in this paper showed the shear dilation mechanism in the shear dilation region at a particle scale. It followed that the predicted results of permeability and porosity enhancement are much higher than the triaxial compression experimental results that are measured at a specimen scale; and the predicted results at a field scale are the lowest among these evaluations. At the field scale, it is impossible for Karamay oil sands to generate such shear dilation as strong as that at the specimen scale.

At the specimen scale, the overall induced strains are imposed to the shear bands. It was observed that the formation of localized shear bands exerts significant influence on the overall geotechnical and hydraulic behavior of the test specimens. Development of localized shear bands yields nonunique bifurcated modes making the data interpretation complicated and difficult [27]. In this paper, it was assumed that permeability changes are equal in all directions, and the model does not reflect the directional behavior of permeability changes, just like the Kozeny-Carman equation, which correlates the change in permeability with the change in porosity. Many researchers [27, 28, 49, 50] discussed the permeability anisotropy induced by localized shear bands. In further research, theoretical and laboratory works will be conducted to establish the permeability changes in three dimensions.

In fact, this paper proposed the transscale evaluation methods of shear dilation effects. Firstly, the ESEM images at a microscale (or grain scale) were used for evaluating the shear dilation capability by particle packing theory. The systematic packing of spheres with particular relation to porosity and permeability was proposed by Westman and Hugill [25] and developed by many researchers $[26,37,51,52]$. 
For the geomechanical analyses in oil sand reservoirs, Westman and Hugill and Graton and Fraser $[25,26]$ used this method to discover the evolution of changes in permeability under shear. For the second method, the triaxial compression tests at a core scale (usually cylindrical standard cores of $25 \mathrm{~mm} \times 50 \mathrm{~mm}$, diameter $\times$ length) were widely conducted to study the shear dilation behavior $[8,16,53$, 54]. At the field scale, the injectivity simulations and fluidstructure coupled analyses were mainly studied by the numerical approaches like the finite element method [13, $14,32,34,36,41]$. This paper used three scales to predict the dilation effects and obtained good results for the guidance of water injection.

The critical parameters that affect dilation are as follows: (1) the natural compositions and structures of oil sands, such as whether there is enough contact between grains or not, and the arrangement mode between grains; and (2) environmental conditions: stress (path and history), pore pressure, and temperature. In this paper, the contact between grains was considered in the model by introducing the coordination number $N$, and the arrangement mode between grains was described by the arrangement angle $\alpha$. Besides, this study established the relation between the model and strains by equations (19)-(21). In this regard, if the stress-strain response under different temperatures can be obtained, the effective stress (total stress subtracting pore pressure, for loose oil sands) and temperature can be considered in the model. This will be studied in further research. Besides these critical parameters, the following parameters can also influence the dilation behavior, such as the amount of bitumen and clay that are filled between solid grains, the shape of grains, and the particle size distribution of grains. In reality, this model was based on some reasonable assumptions: (1) the bitumen and clay are filled in between the solid grains, which means the solid grains are dominant in volume; (2) the solid grains are all spheres; (3) the particle sizes of grains are the same; (4) the solid grains are rigid; and (5) environmental factors (e.g., temperature) are not considered.

Simplifying the particle system by using monosized spherical particles has been widely discussed across different industries. Simplicity is propitious to obtain analytical solutions, calculation efficiency, a better understanding of the mechanics, and convenience for field engineers, while it also reduces the evaluation accuracy. In reality, whether simplicity is proper nor not is dependent upon the geomaterials studied. For soils and the sandstones with even and spherical grains, simplicity is reasonable. But for other rocks, a more realistic particle system should be used to embody the nonspherical particles, various particle sizes, initial sorting, and packing structures. Oil sands are a kind of unconsolidated sandstones, and they can be regarded as monosized spherical particles, according to this study and previous studies of Canadian oil sands $[27,28]$. The average method was used to eliminate the difference of solid grain diameter and irregularity. Many methods including the discrete element method and the probability density equation can be used for an accurate modeling of these rocks with complex structures like fractures.
The ESEM images in a vision field or even several vision fields can roughly represent the information of the whole reservoir, but there are possibly considerable errors if the selected samples are significantly different from the structures. In this paper, the particle distributions of the oil sands were assumed to be like those of a soil that is almost evenly arranged, but the reservoir heterogeneity in the Karamay oil sand reservoir is very strong because of the presence of mud and sandstone stringers $[8,32]$. The influence of reservoir heterogeneity on the SAGD process was also discussed by other researchers [55-57]. Like the soil, the anisotropy in oil sand reservoirs in this paper was not considered. Wong [28] developed an ideal 3D mathematical model considering the anisotropy based on the particle packing theory, which can be used in a reservoir with a strong anisotropy. Many measurements (i.e., conducting more ESEM experiments and sampling more uniformly) can be used to reduce the predicted errors induced by not considering the reservoir heterogeneity and anisotropy.

In this paper, the shear dilation capability (volumetric strain) under the tested conditions corresponding to the actual reservoir stresses induced by the field operations was simulated by the drained triaxial compression experiments. Apart from the shear dilation, the tensile parting dilation also plays an important role in the oil sand reservoir deformation $[7,32]$. The tensile parting dilation capability (TPDC) can be evaluated by the volumetric strain by the triaxial hydrostatic compression experiments $[3,7,16]$. The evaluation method by the injection data is very dependent upon the effective dilation area, where the porosity and permeability are effectively improved. In this paper, a minimum effective dilation area was used for analyses. The effective radius is $5 \mathrm{~m}$ in this paper, and $6 \mathrm{~m}$ was also selected by Gao et al. [3]. Lin et al. $[32,41]$ discussed the dilation area using the hydraulic communication parameter in the Karamay oil sand reservoir by FEM (finite element method), which can be used to evaluate the effective radius.

All in all, the end purpose of this paper is to evaluate the current shear dilation capability, and to see how much of the residual shear dilation potential is left. The next task will be focused on how to utilize these remaining potentials. Corresponding optional operations will be discussed by the triaxial compression experiments to find out a proper confining stress, pore pressure, temperature, and maybe some additives in the injection water, and by the field recorded data analyses to search for a proper injection pressure, rate, temperature, fluid, and maybe frequency such as the constant, step-bystep, and pulse-type injections.

\section{Conclusion}

This paper proposed the shear dilation and permeability improvement capability/potential to describe the evolutions of porosity and permeability changes under water injectioninduced shear. The 2D and 3D mathematical models based on the Karamay oil sand microstructures derived from ESEM were established to predict the shear dilation effects, which were represented by these new definitions through the particle packing theory. The field case study for a wellpair was 
discussed to evaluate the shear dilation capability at three different scales including the ESEM microstructure, laboratory triaxial compression tests by cores, and analyses by field injection data.

Major conclusions through an application on the wellpair A-2 in area A of the Karamay Fengcheng oil field can be drawn as follows:

(1) These petrophysical properties of Karamay oil sands, including the mineral composition, porosity/permeability characteristics, microstructure, and pore fluid properties, indicate that the Karamay oil sands possess a basic geomechanical condition for shear dilation. It has an excellent shear dilation and permeability improvement potential because of the highcontent quartz, breccia-shaped grains with sharp edges, and interlocked structures

(2) The shear dilation and permeability improvement capabilities increase with the increasing arrangement angle. The increase is sharp at the beginning of dilation but shows little change at the end of dilation. The maximum shear dilation and permeability improvement capabilities reach 0.15 and 0.41 for the $2 \mathrm{D}$ and $3 \mathrm{D}$ models, respectively, when the oil sand reservoir is adequately disturbed and the arrangement angle is exactly forced to a right angle of $90^{\circ}$ by a perfect operation. These results indicate that the shear dilation effects by water injections are very considerable in terms of porosity (volume change) and permeability

On the contrary, a lower arrangement angle indicates a higher potential of shear dilation or permeability improvement. The maximum shear dilation and permeability improvement potentials reach 16.33 and 12.37 for the 2D and $3 \mathrm{D}$ models, respectively, when a reservoir possesses a virgin arrangement angle of $60^{\circ}$. These results tell us that a reservoir with a lower arrangement angle has a higher potential of shear dilation and permeability increase.

Triaxial compression and permeability experiments were conducted to validate the theoretical models. The experimental axial strain-volumetric strain curves can be fitted well by a $2 \mathrm{D}$ theoretical model. The permeability change measured by experiments can reach $0.4 \sim 0.45$ times that predicted by theoretical models. The coordination number for the actual particle packing body was used to correct the ideal model, so as to interpret the differences between experimental data and model prediction.

(3) This paper proposed the transscale evaluation methods of shear dilation effects. The shear dilation capabilities predicted by the ESEM, triaxial compression experiments, and field injection information are $0.135,0.07$, and less than 0.012 , respectively, which indicate that the actual (shear) dilation capability is difficult to be used by present field operations, although the oil sand itself has a very high (shear) dilation potential. Therefore, it is desired for engineers to design adequate measures to efficiently utilize the high potential of (shear) dilation

\section{Nomenclature}

$\begin{array}{ll}\Delta h_{1}, \Delta h_{2}: & \begin{array}{l}\text { Height increase of the representative } \\ \text { volume element with the shear dilation }\end{array} \\ k, k_{0}: & \text { The current absolute permeability and } \\ & \text { the initial absolute permeability, } \\ & \text { respectively } \\ & \text { The perfect (maximum) absolute } \\ k_{\max }, k_{\mathrm{i}}: & \text { permeability and the initial absolute } \\ & \text { permeability, respectively } \\ k_{\mathrm{w} 0}: & \text { The effective permeability to water } \\ N: & \text { The coordination number } \\ \mathrm{PIC}: & \text { Permeability improvement capability } \\ R: & \text { The radius of solid grains } \\ \mathrm{RVE}: & \text { The representative volume element } \\ \mathrm{SDC}: & \text { Shear dilation capability } \\ V, V_{0}: & \text { The current total volumes and the ini- } \\ V_{\max }, V_{\min }, \text { and } V_{\mathrm{i}}: & \text { The perfect (maximum) total volumes, } \\ & \text { the minimum volume, and the initial } \\ V_{\mathrm{s}}: & \text { total volumes, respectively } \\ V_{\mathrm{inj}}: & \text { The total volume of all the round solid } \\ \alpha_{\mathrm{i}}: & \text { grains } \\ \varepsilon_{\mathrm{a}}: & \text { The cumulative injection volume } \\ \varepsilon_{\mathrm{v}}: & \text { The initial arrangement angle } \\ \varphi, \varphi_{0}: & \text { The axial strain } \\ & \text { The volumetric strain } \\ & \text { The porosity and the initial porosity, } \\ & \text { respectively. }\end{array}$

\section{Data Availability}

The data used to support the findings of this study are available from the corresponding author upon request.

\section{Conflicts of Interest}

The authors declare no conflict of interest.

\section{Authors' Contributions}

Y.G. and H.P. contributed in the conceptualization of the study. M.C. contributed in funding acquisition. Y.J. and M.C. contributed in preparing the methodology of the study. M.C. supervised the study. Y.G. and H.P. contributed in writing the study.

\section{Acknowledgments}

This work was supported by the National Natural Science Foundation of China (NSFC) for Major Projects (grant numbers 51490651, 51325402, and 51404281).

\section{References}

[1] J. G. Speight, The Chemistry and Technology of Petroleum, CRC Press, 5th edition, 2014.

[2] P. M. Collins, "Geomechanical effects on the SAGD process," in SPE International Thermal Operations and Heavy Oil Symposium, Calgary, Alberta, Canada, 2005. 
[3] Y. Gao, M. Chen, B. Lin, and Y. Jin, "Experimental investigation on compressibility of karamay oil sands under water injection," in 51st U.S. Rock Mechanics/Geomechanics Symposium, American Rock Mechanics Association, San Francisco, CA, USA, 2017.

[4] M. B. Dusseault and N. R. Morgenstern, "Shear strength of Athabasca oil sands," Canadian Geotechnical Journal, vol. 15, no. 2, pp. 216-238, 1978.

[5] M. B. Dusseault and N. R. Morgenstern, "Locked sands," Quarterly Journal of Engineering Geology and Hydrogeology, vol. 12, no. 2, pp. 117-131, 1979.

[6] H. Pang, Y. Jin, B. Lin, Y. Gao, J. Dong, and M. Fan, "Mesostructure change in land facies Karamay oil sand reservoirs under water injection," in 51st U.S. Rock Mechanics/Geomechanics Symposium, vol. 28, San Francisco, California, USA, 2017.

[7] Y. Yuan, B. Xu, and B. Yang, "Geomechanics for the thermal stimulation of heavy oil reservoirs-Canadian experience," in SPE Heavy Oil Conference and Exhibition, Kuwait City, Kuwait, 2011.

[8] B. Lin, Y. Jin, H. Pang, and A. Cerato, "Experimental investigation on dilation mechanisms of land-facies Karamay oil sand reservoirs under water injection," Rock Mechanics and Rock Engineering, vol. 49, no. 4, article 817, pp. 1425-1439, 2016.

[9] A. Settari, P. R. Kry, and C.-T. Yee, "Coupling of fluid flow and soil behavior to model injection into uncemented oil sands," Journal of Canadian Petroleum Technology, vol. 28, no. 1, pp. 81-92, 1989.

[10] M. Carlson, "SAGD and geomechanics," Journal of Canadian Petroleum Technology, vol. 42, no. 6, pp. 19-25, 2003.

[11] P. M. Collins, "Geomechanical effects on the SAGD process," SPE Reservoir Evaluation and Engineering, vol. 10, no. 4, pp. 367-375, 2007.

[12] J. G. Agar, Geotechnical behavior of oil sands at elevated temperatures and pressures, University of Alberta, Alberta, 1984, (Ph.D. thesis).

[13] R. Chalaturnyk and J. D. Scott, "Geomechanics issues of steam assisted gravity drainage," in SPE International Heavy Oil Symposium, Calgary, Alberta, Canada, 1995.

[14] R. J. Chalaturnyk and P. Li, "When is it important to consider geomechanics in SAGD operations," Journal of Canadian Petroleum Technology, vol. 43, no. 4, pp. 53-61, 2004.

[15] S. K. Leung, P. R. Kry, and R. C. K. Wong, "Visualization of deformation in unconsolidated Athabasca oil sand," in SPE International Heavy Oil Symposium, Calgary, Alberta, Canada, 1995.

[16] R. C. K. Wong, W. E. Barr, and P. R. Kry, "Stress-strain response of Cold Lake oil sands," Canadian Geotechnical Journal, vol. 32, pp. 220-235, 1993.

[17] J. D. Scott, S. A. Proskin, and D. P. Adhikary, "Volume and permeability changes associated with steam stimulation in an oil sands reservoir," Journal of Canadian Petroleum Technology, vol. 33, no. 7, pp. 44-52, 1994.

[18] R. C. K. Wong, "Mobilized strength components of Athabasca oil sand in triaxial compression," Canadian Geotechnical Journal, vol. 36, pp. 718-735, 1999.

[19] D. H. Doan, P. Delage, and J. F. Nauroy, "Microstructural characterization of a Canadian oil sand," Canadian Geotechnical Journal, vol. 49, pp. 1212-1220, 2012.

[20] A. Touhidi-Baghini, Absolute permeability of McMurray Formation oil sands at low confining stresses, University of Alberta, Edmonton, 1998, (Ph.D. thesis).
[21] A. Touhidi-Baghini and J. D. Scott, "Absolute permeability changes of oil sand during shear," in The 51st Canadian Geotechnical Conference, pp. 729-736, Edmonton, Alberta, 1998.

[22] K. Oldakowski, Stress induced permeability changes of Athabasca oilsands, University of Alberta, Edmonton, 1994, (M.S. thesis).

[23] D. P. Yale, T. Mayer, and J. Wang, "Geomechanics of oil sands under injection," in 44th US Rock Mechanics Symposium and 5th US-Canada Rock Mechanics Symposium, Salt Lake City, 2010.

[24] B. Xu, "Consideration of geomechanics for in-situ bitumen recovery in Xinjiang, China," in SPE Heavy Oil Conference-Canada, Calgary, Alberta, Canada, 2013.

[25] A. E. R. Westman and H. R. Hugill, "The packing of particles," Journal of the American Ceramic Society, vol. 13, no. 10, pp. 767-779, 1930.

[26] L. C. Graton and H. J. Fraser, "Systematic packing of spheres: with particular relation to porosity and permeability," Journal of Geology, vol. 43, 8, Part 1, pp. 785-909, 1935.

[27] R. C. K. Wong and Y. Li, "A deformation-dependent model for permeability changes in oil sand due to shear dilation," Journal of Canadian Petroleum Technology, vol. 40, no. 8, pp. 37-44, 2001.

[28] R. C. K. Wong, "A model for strain-induced permeability anisotropy in deformable granular media," Canadian Geotechnical Journal, vol. 40, pp. 95-106, 2003.

[29] J. G. Agar, N. R. Morgenstern, and J. D. Scott, “Geotechnical testing of Alberta oil sands at elevated temperatures and pressures," in The 24th U.S. Symposium on Rock Mechanics (USRMS), College Station, TX, USA, 1983.

[30] Y. Gao, M. Chen, and B. Lin, "Modeling of reservoir deformation upon preheating in SAGD wells considering phase change of bitumen," in 52nd US Rock Mechanics/Geomechanics Symposium, Seattle, Washington, USA, 2018.

[31] H. Pang, Y. Jin, and Y. Gao, "Evaluation of elastic property changes in Karamay oil sand reservoir during thermal stimulation," Energy Science \& Engineering, vol. 7, pp. 1233-1253, 2019.

[32] B. Lin, S. Chen, and Y. Jin, "Evaluation of reservoir deformation induced by water injection in SAGD wells considering formation anisotropy, heterogeneity and thermal effect," Journal of Petroleum Science and Engineering, vol. 157, pp. 767779, 2017.

[33] ASTM D4124-09, Standard Test Method for Separation of Asphalt into Four Fractions, ASTM International, 2018.

[34] P. Li, R. J. Chalaturnyk, and M. Polikar, "Issues with reservoir geomechanical simulations of the SAGD process," Journal of Canadian Petroleum Technology, vol. 43, no. 5, 2004.

[35] W. S. Tortike and S. M. Farouq Ali, "Reservoir simulation integrated with geomechanics," Journal of Canadian Petroleum Technology, vol. 32, no. 5, pp. 28-37, 1993.

[36] P. Li and R. J. Chalaturnyk, "History match of the UTF phase A project with coupled reservoir geomechanical simulation," Journal of Canadian Petroleum Technology, vol. 48, no. 1, pp. 29-35, 2009.

[37] G. D. Scott, "Packing of spheres," Nature, vol. 188, no. 4754, pp. 908-909, 1960.

[38] W. O. Smith, P. D. Foote, and P. F. Busang, "Packing of homogeneous spheres," Physics Review, vol. 34, pp. 1271-1274, 1929. 
[39] K. Ridgway and K. J. Tarbuck, "Random packing of spheres," British Chemical Engineering, vol. 12, pp. 384-388, 1967.

[40] H. Pang, Y. Jin, M. Chen, B. Lin, and Q. Shan, “A simulation model of land-facies Karamay oil sand reservoirs under water injection," in International Petroleum Technology Conference, Bangkok, Thailand, 2016.

[41] B. Lin, Y. Jin, and S. Chen, "A criterion for evaluating the efficiency of water injection in oil sand reservoirs," Journal of Petroleum Science and Engineering, vol. 149, pp. 322-330, 2017.

[42] Y. Gao, M. Chen, B. Lin, and Y. Jin, "An analytical model of hydraulic dilation area for Karamay oil sand reservoir under water injection in SAGD wells," Journal of Petroleum Science and Engineering, vol. 179, pp. 1090-1101, 2019.

[43] M. D. Bolton and C. K. Lau, "Scale effects arising from particle size," in Centrifuge 88: The International Conference on Geotechnical Centrifuge Modelling, pp. 127-131, Paris, France, 1988.

[44] J. P. Bardet and J. Proubet, "Shear-band analysis in idealized granular material," Journal of Engineering Mechanics, vol. 40, no. 3, pp. 397-415, 1992.

[45] J. P. Bardet and J. Proubet, "A numerical investigation of the structure of persistent shear bands in granular media," Géotechnique, vol. 41, no. 4, pp. 599-613, 1991.

[46] I. Vardoulakis and B. Graf, "Calibration of constitutive models for granular materials using data from biaxial experiments," Géotechnique, vol. 35, no. 3, pp. 299-317, 1985.

[47] H. B. Muhlhaus and I. Vardoulakis, "The thickness of shear bands in granular materials," Géotechnique, vol. 37, no. 3, pp. 271-283, 1987.

[48] Y. Y. Cai, Study on the size effect and shear band of soil material, Beijing Jiaotong University, Beijing, 2017, (M.S. thesis).

[49] R. C. K. Wong, "Strain-induced anisotropy in fabric and hydraulic parameters of oil sand in triaxial compression," Canadian Geotechnical Journal, vol. 40, pp. 489-500, 2003.

[50] J. Dautriat, G. Gland, J. Guelard, A. Dimanov, and J. L. Raphanel, "Axial and radial permeability evolutions of compressed sandstones: end effects and shear-band induced permeability anisotropy," Pure and Applied Geophysics, vol. 166, pp. 1037-1061, 2009.

[51] D. E. Hudson, "Density and packing in an aggregate of mixed spheres," Journal of Applied Physics, vol. 20, no. 2, pp. 154-162, 1947.

[52] J. E. Funk and D. R. Dinger, Predictive Process Control of Crowded Particulate Suspensions: Applied to Ceramic Manufacturing, Kluwer Academic Publishers, Springer, Boston, MA, USA, 1994.

[53] J. G. Agar, N. R. Morgenstern, and J. D. Scott, "Shear strength and stress-strain behavior of Athabasca oil sand at elevated temperatures and pressures," Canadian Geotechnical Journal, vol. 24, pp. 1-10, 1987.

[54] A. Settari, Y. Ito, and N. Fukushima, "Geotechnical aspects of recovery processes in oil sands," Canadian Geotechnical Journal, vol. 30, pp. 22-33, 1993.

[55] G. Yang and R. M. Butler, "Effects of reservoir heterogeneities on heavy oil recovery by steam-assisted gravity drainage," Journal of Canadian Petroleum Technology, vol. 31, no. 8, pp. 37-43, 1992.
[56] Q. Chen, M. G. Gerristen, and A. R. Kovscek, "Effects of reservoir heterogeneities on the steam-assisted gravity drainage process," in SPE Annual Technical Conference and Exhibition, Anaheim, CA, USA, 2007.

[57] W. Zhang, S. Youn, and Q. Doan, "Understanding reservoir architectures and steam-chamber growth at Christina Lake, Alberta, by using 4D seismic and crosswell seismic imaging," SPE Reservoir Evaluation \& Engineering, vol. 10, no. 5, pp. 446-452, 2007. 

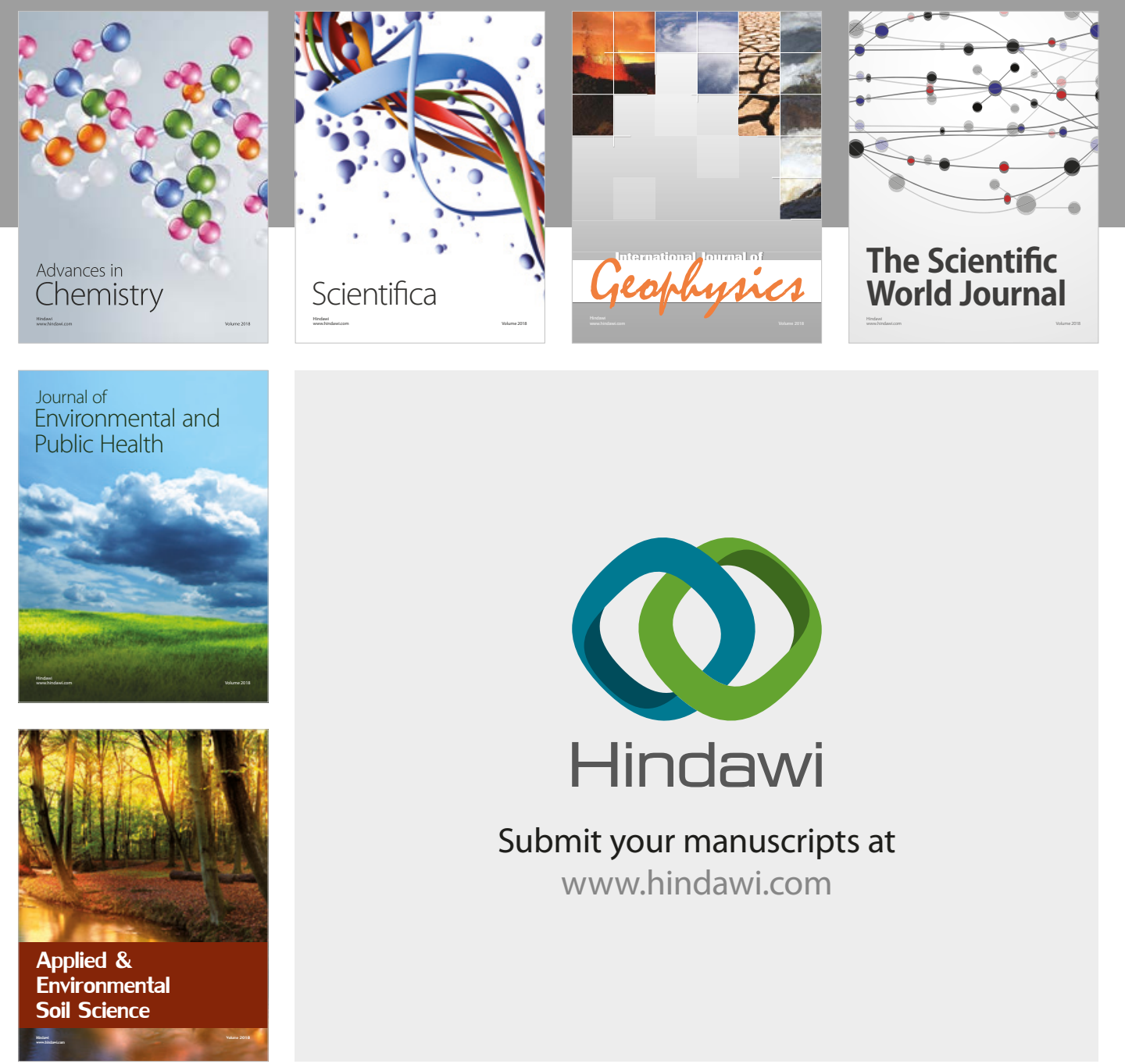

The Scientific

\section{World Journal}
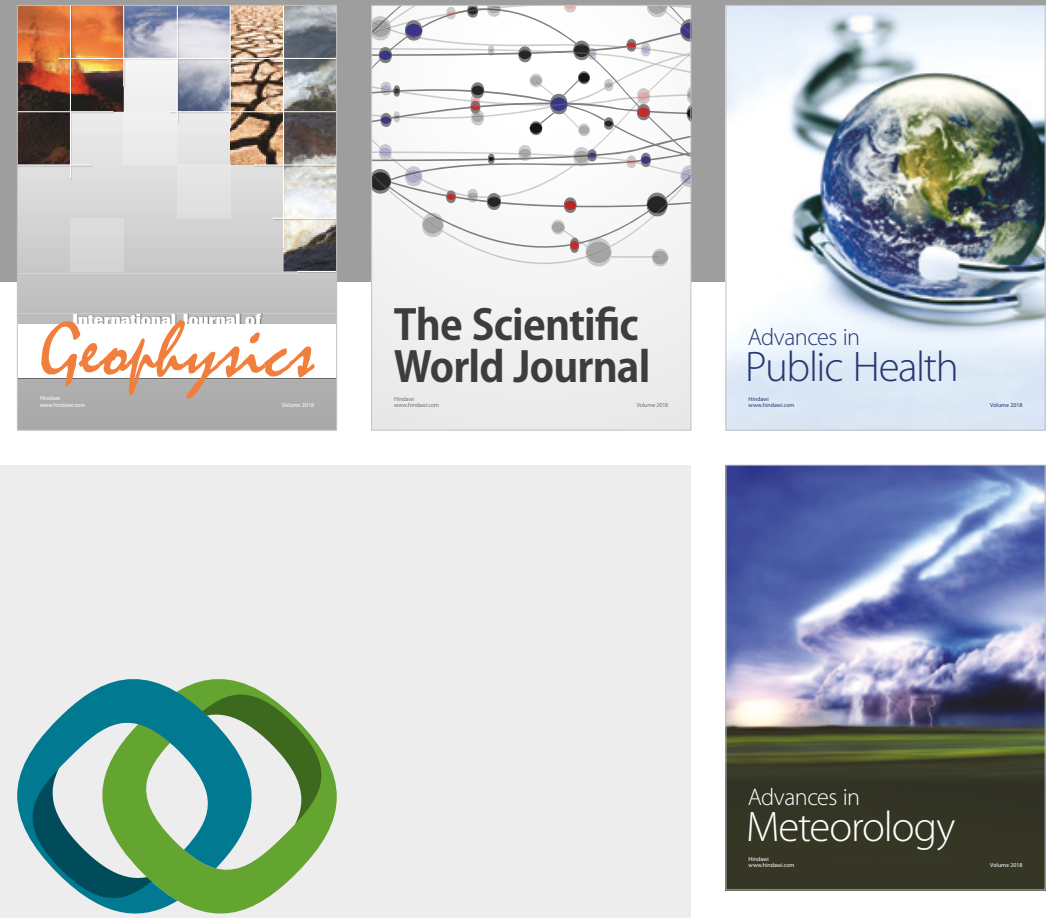

Advan

Public Health

\section{Hindawi}

Submit your manuscripts at

www.hindawi.com
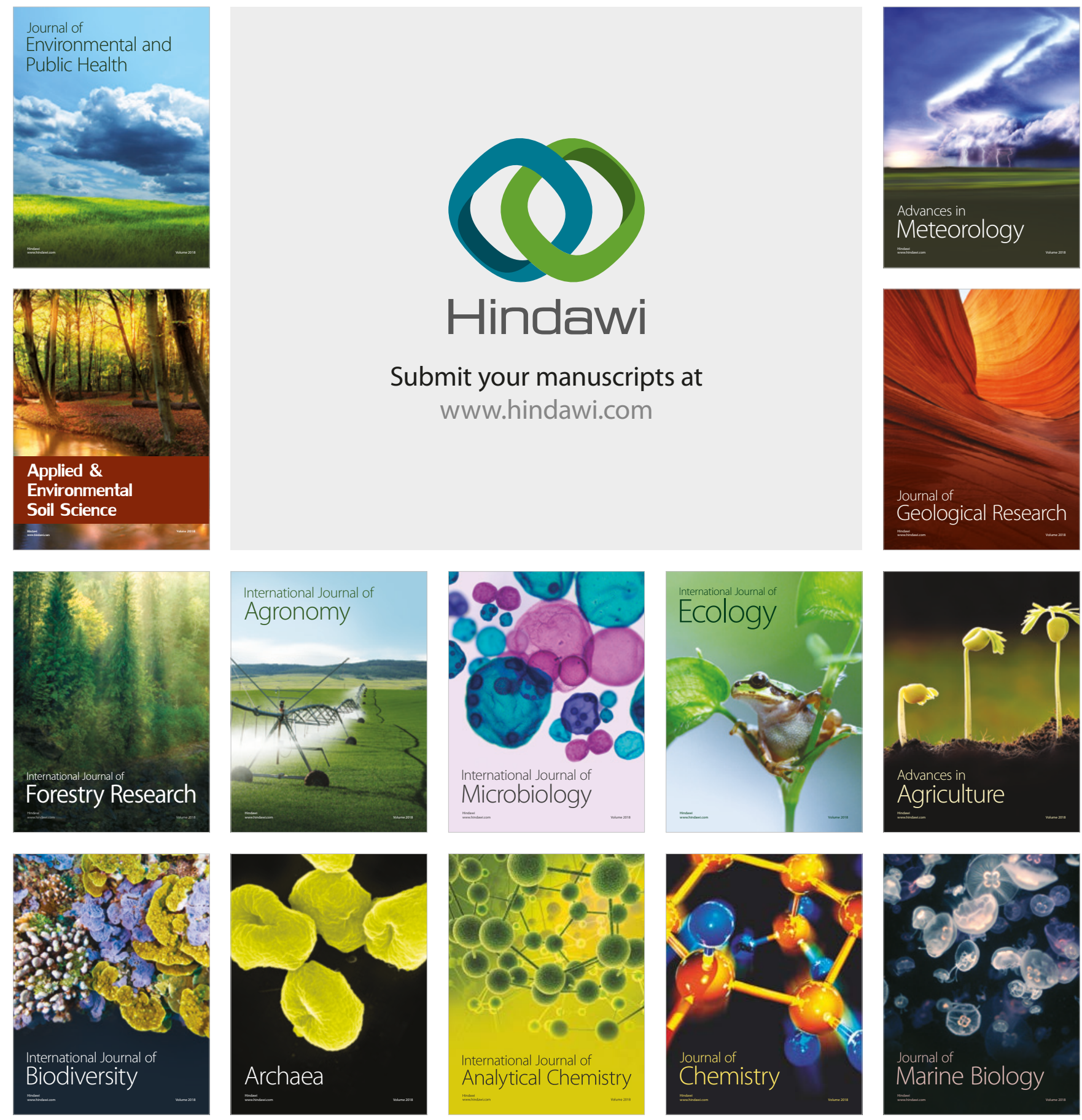